\title{
Electrical Components for Marine Renewable Energy Arrays: A Techno-Economic Review
}

\author{
Adam J. Collin 1,* (D), Anup J. Nambiar ${ }^{1}$, David Bould ${ }^{1}$, Ben Whitby ${ }^{2}$, M. A. Moonem ${ }^{3}$ \\ Benjamin Schenkman ${ }^{3}$, Stanley Atcitty ${ }^{3}$ (D), Paulo Chainho ${ }^{4}$ and Aristides E. Kiprakis ${ }^{1}$ \\ 1 School of Engineering, The University of Edinburgh, Edinburgh, Scotland EH9 3DW, UK; \\ A.Nambiar@ed.ac.uk (A.J.N.); David.Bould@ed.ac.uk (D.B.); aristides.kiprakis@ed.ac.uk (A.E.K.) \\ 2 ITPEnergised, Bristol BS1 5QT, UK; ben.whitby@itpenergised.com \\ 3 Sandia National Laboratories, Albuquerque, New Mexico, NM 87185, USA; \\ mmoonem@sandia.gov (M.A.M.); mmoonem@sandia.gov (B.S.); satcitt@sandia.gov (S.A.) \\ 4 WavEC-Offshore Renewables, 1400-119 Lisbon, Portugal; paulo@wavec.org \\ * Correspondence: adam.collin@ieee.org; Tel.: +44-(0)131-650-5069
}

Received: 1 November 2017; Accepted: 21 November 2017; Published: 27 November 2017

\begin{abstract}
This paper presents a review of the main electrical components that are expected to be present in marine renewable energy arrays. The review is put in context by appraising the current needs of the industry and identifying the key components required in both device and array-scale developments. For each component, electrical, mechanical and cost considerations are discussed; with quantitative data collected during the review made freely available for use by the community via an open access online repository. This data collection updates previous research and addresses gaps specific to emerging offshore technologies, such as marine and floating wind, and provides a comprehensive resource for the techno-economic assessment of offshore energy arrays.
\end{abstract}

Keywords: marine energy; offshore energy; cost; database; cables; connectors; transformers; electrical components

\section{Introduction}

The theoretical power of marine renewable energy (MRE) worldwide is vast, with an estimated $1200 \mathrm{TWh} /$ year available from tidal resources and 29,500 TWh/year in ocean waves [1]. In Europe alone, it is thought that up to $100 \mathrm{GW}$ of MRE could be installed by 2050 [2], with a global projection of $300 \mathrm{GW}$ [1]. However, at the end of 2016, only $14 \mathrm{MW}$ had been installed in Europe [3], compared to $141.1 \mathrm{GW}$ of onshore wind and $12.6 \mathrm{GW}$ of offshore wind [4]. MRE clearly has potential to contribute to a low carbon future, but currently lags behind wind energy in terms of technology maturity. Progression to a standardised electrical architecture is a key driver for the industry to exploit economies of scale across the supply chain. To understand how these electrical networks may be realised, the technological capabilities and future development of the main components must be assessed.

This is the motivation of this paper, which presents a review of the status of the main electrical components of MRE arrays. An appraisal of the industry is performed to justify the scope of the study and to provide a collection of data, which serves the current needs of the sector and also stands up to medium-term time scale challenges, as it progresses from individual device to array scale. These needs have been defined by analysing market reports and through discussions with major developers.

The main contribution of this paper is in the data collection of electrical components, which addresses the needs of the MRE industry. Components are assessed using data collected from the MRE sector, the offshore wind and oil and gas (O\&G) sectors. This data collection provides electrical parameters for use in load flow studies, mechanical data for use in logistic analysis and cost 
functions for techno-economic studies. Cost data have been obtained from literature and industrial sources (which are anonymized and not cited). As cost data are sensitive to a number of factors, e.g., raw material cost, all cited data are valid for the year of the original reference, with all others taken as cost at the time of publication. This study fills a gap in existing literature as it considers components and ratings that are not included in traditional offshore wind farms. Although the data presented are primarily intended as a resource for the analysis of MRE arrays, they contain a large volume of information and provide a useful database for the offshore energy research community in general. In particular, the information on connectors, dynamic cables and subsea components has considerable value to research in the emerging floating offshore wind industry. As such, the quantitative data collected for each component is made freely available for use by the community at [5].

The paper is divided into three main sections. Section 2 presents a brief review of the status of the MRE sector. Sections 3-8 introduce the main electrical components and summarise the data collection effort. The online repository is described in Section 9. Conclusions are discussed in Section 10. All collected cost data are included in Appendix A.

\section{Offshore Network Review}

An offshore network can be divided into four main subsystems: the intra-array network, which connects the ocean energy converters (OECs), offshore collection point(s), the transmission system and the point of connection to the onshore network, i.e., the point of common coupling (PCC). A simplified schematic of the subsystems is shown in Figure 1. The main electrical components within the electrical network can be classified into six categories. These are defined in Table 1, with components included beside the category headers.

Cables collect and transmit power and communication signals within the array, and connectors allow for a non-permanent connection of different parts of the electrical system. Transformers are used to convert between voltage levels for the purpose of power transmission; they are typically utilised to step-up the voltage at the device level from low-voltage $(\mathrm{LV},<1 \mathrm{kV})$ to medium voltage (MV, 1-35 kV) and also within the offshore collection point to increase the voltage to high voltage (HV, $>35 \mathrm{kV})$ for exporting to shore. They also provide transformation for LV auxiliary supplies and measurement purposes. Switchgear components facilitate the safe installation, operation and maintenance of the array. The power quality component category primarily relates to power electronics-based FACTS devices, but also includes other static equipment used to enhance controllability and power quality.

Table 1. Electrical component categories.

\begin{tabular}{cc}
\hline Category & Component (s) \\
\hline Cables & Static, dynamic \\
Connectors & Wet-mate, dry-mate, T-off \\
Transformers & Power, grounding, auxiliary and measurement \\
Switchgear & Circuit breakers, relays, fuses and disconnectors \\
Power quality & Reactive compensation, flexible AC transmission system and harmonic filters \\
Collection points & Hubs, substation \\
\hline
\end{tabular}

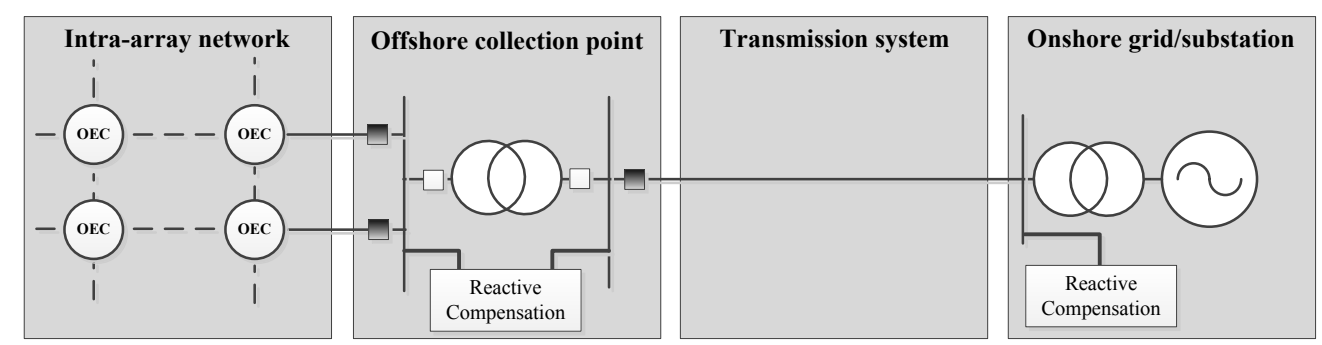

Figure 1. Simplified electrical network for offshore arrays. 
The development of offshore networks has been led by the offshore wind sector, which has high levels of technological convergence (whereby a given concept, e.g., the horizontal axis turbine, becomes the dominant technology in use) in all areas. Turbine terminal voltage is at $30-36 \mathrm{kV}$, and the intra-array network is predominantly a radial network configuration. The offshore collection point will be a surface piercing platform with step-up transformers to increase the voltage of the transmission system to $110-220 \mathrm{kV}$. Such extensive technological convergence is not evident in the MRE sector with many technology concepts competing for market share.

\subsection{OEC Device Level}

There is some technological convergence of tidal stream technologies and several are entering the phase of extensive sea trials. Horizontal axis turbines are the most mature technology and can be considered to have reached commercialisation. However, despite three quarters of tidal developers focussing on horizontal axis turbines, other technologies, such as ducted turbines and tidal kites, are also receiving considerable attention and are close to demonstrating commercial viability [3]. Wave technology is slightly further behind, and there is little evidence of technological convergence at the device level. An overview of the possible power take off (PTO) technologies (i.e., mechanisms intended to convert mechanical movement into electrical power) is beyond the scope of this work, but can be found in [6]. As a result of variations in the PTO, competing wave devices can have significantly different output electrical characteristics, placing different requirements on the supporting electrical architecture.

As shown in Figure 2a, a wide range of output voltages and powers is currently under consideration by device developers. Clustering around 6 and $11 \mathrm{kV}$ is a result of compatibility with test site connections. A thorough review of generators and converters employed in OECs is available at $[7,8]$.

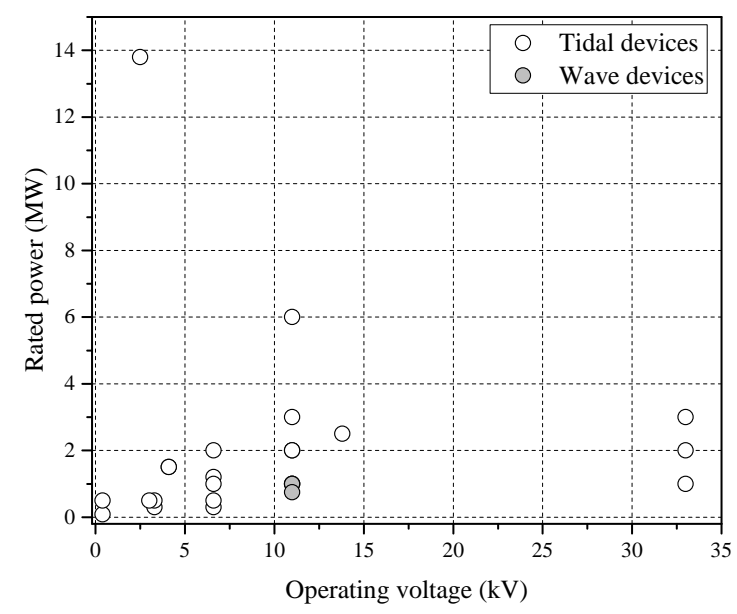

(a)

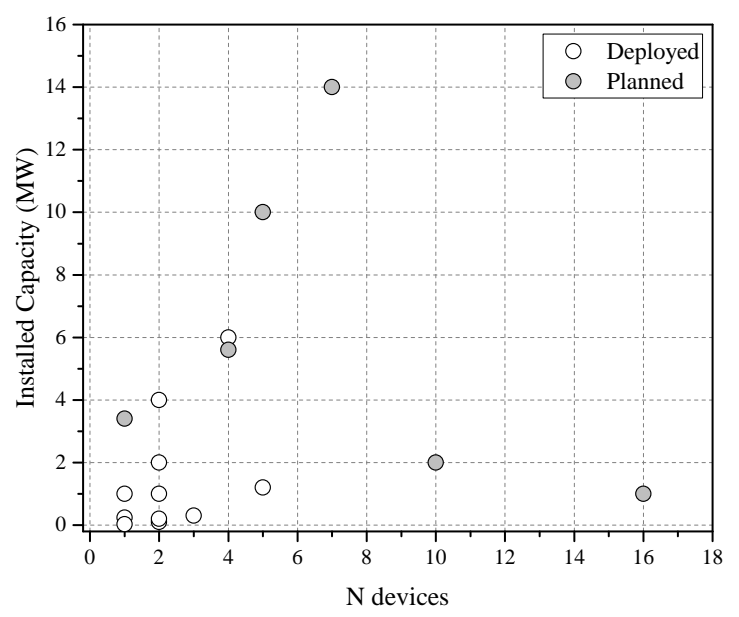

(b)

Figure 2. Overview of the ocean energy converter (OEC) industry: (a) devices (b) arrays. Based on data in [3].

\subsection{Array Level}

Although many wave and tidal energy arrays have been proposed in recent years, few have entered the deployment phase. A number of major studies, including [9-13], have investigated likely electrical infrastructures for larger ( $>30 \mathrm{MW}$ ) arrays. A number of solutions are presented: ranging from radial networks to hub and spoke configurations; DC designs, AC designs and hybrid AC-DC designs; onboard converters and transformers, offboard converters and transformers and centralised power conditioning units. However, the conclusions from such studies are often contradictory and can be biased by preference for a given vendor. Furthermore, although arrays of this scale will be required 
to reduce costs and allow MRE technologies to compete with other forms of electricity generation, the industry is still far from achieving this level of deployment.

Small commercial tidal arrays are beginning to come online and will provide valuable insight for the industry moving forward. In particular, two significant projects (MeyGen [14] and Bluemull Sound [15]) are now delivering electricity to the U.K. grid. Both arrays are in construction while also operating and delivering electricity to the grid at partial capacity. The arrays have four and five devices, respectively, each with individual export cables to shore. MeyGen is the largest developed and has consent for a 15-MW connection to the distribution network, while the proposed larger site (398 MW) will connect to the transmission network at $132 \mathrm{kV}$ [8]. All power conditioning equipment is onshore, with horizontal directional drilling (HDD) utilised to bring each 2-km cable back on shore [8]. At Bluemull, each 0.8-1-km cable is surface laid and covered by external protection [16].

Further examples of pre-commercial and demonstration projects are included in Figure $2 \mathrm{~b}$. These are exclusively tidal arrays, as there are no notable array-scale developments of wave energy converters. Although the estimated tidal energy resource is significantly less than the estimated wave energy resource, the predictability of tides presents advantages over other renewable energy technologies $[17,18]$, for both network operators and investors. Furthermore, the vast majority of potential tidal sites in the U.K. are located within $10 \mathrm{~km}$ from shore in water depths less than $80 \mathrm{~m}$ [19]. Due to the nature of operation some wave devices are suited to deeper water areas, up to $200 \mathrm{~m}$, which can be located up to $50 \mathrm{~km}$ offshore [20]. These more volatile waters present different requirements for device survivability and also require more expensive electrical infrastructure to export power to the shore.

\section{Cables}

Within the offshore array, submarine cables facilitate the transfer of power from the OEC to the onshore grid. In addition to transferring power, submarine cables serve the crucial role of transmitting communication signals between the array equipment and the shore, which are vital for monitoring and control of electrical components within the network. Cables are classified into two categories: static cables and dynamic cables. This classification is essentially defined by the expected movement of the cable: static cables are typically buried within the seabed, or secured to the surface using external protection, while dynamic cables will operate in the water column.

\subsection{Static Cables}

\subsubsection{Functional Description}

Static power cables are used to collect the power generated by the farm through the intra-array electricity network and also to export the generated power from the collection point to the shore. As previously stated, they will also carry communication signals via integrated optical fibres. The purpose of this section is not to present fundamental theory on cable design as several texts, e.g., [21], deal with this complex subject in great depth.

\subsubsection{Current Status}

Submarine cables have been around since the 19th century, when they were used to deliver power across small stretches of water. Since then, their use has been driven by the use of interconnectors for grid stability and resource sharing between countries and the extraction of power generated offshore. There are many technological variations in the cable design, but the limitations and applications of different designs is well understood. Figure 3 outlines the main technologies employed as a function of cable voltage, current rating and distance for a number of wind farms and interconnectors. All reported wind farm cables utilised copper conductors, with the overwhelming majority using cross-linked polyethylene (XLPE) insulation [22,23]. Although $33 \mathrm{kV}$ is the current standard array voltage level, there is some consideration of increasing to $66 \mathrm{kV}$ for offshore wind [24]. 


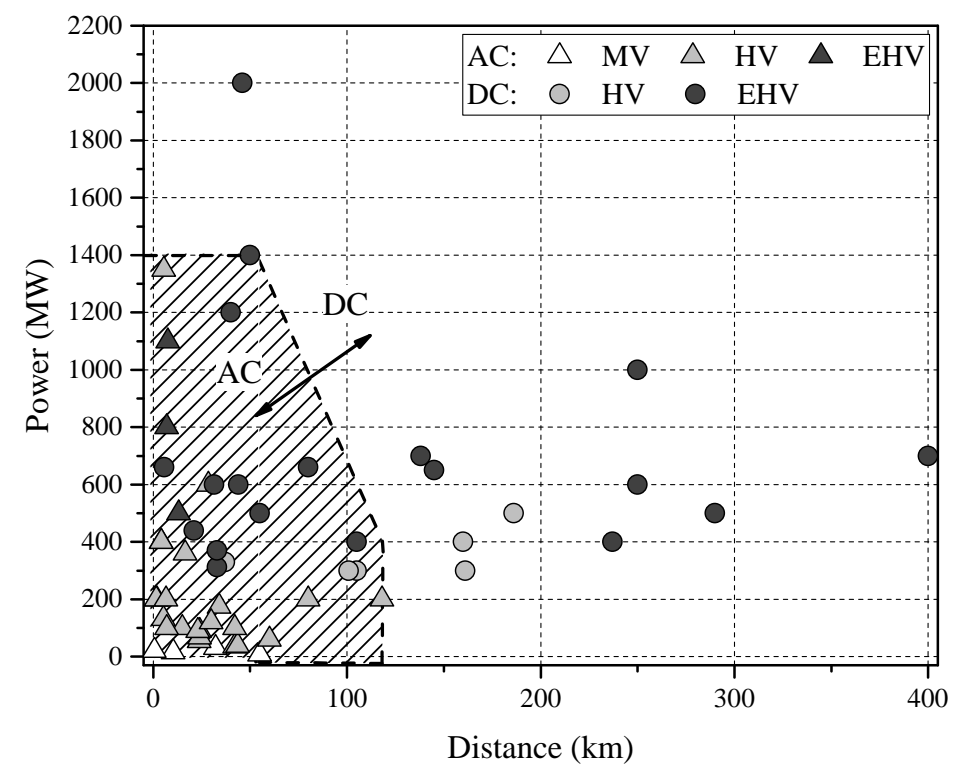

Figure 3. Examples of installed cables and the extent of static cable capability, where the shaded region signifies technically-feasible limits of AC transmission. Data points from [22,23]; feasible limits from [25]. MV, medium voltage; $\mathrm{HV}$, high voltage; EHV, extra high voltage.

\subsubsection{Application in Marine Energy Arrays}

The functional capability of static cables far exceeds the current requirements of the MRE industry. However, there are several specific challenges, which result from the high-energy environments, which must be considered. One impact of this is during the installation phase, regarded as one of, if not the most high risk phases of the cable lifetime [26]. During the installation phase, the cable must support its own weight, and the stress on the cable increases as a function of water depth. Additional forces due to movement of the installation vessel (particularly for smaller cable laying vessels), the catenary support and residual horizontal force on the already laid cable must also be carefully considered to ensure that the manufacturers' bend radius requirement is adhered to.

Once the cable has been installed, tested and enters the operation phase, the marine environment again has an impact on the cable ampacity, as the current carrying capacity of the cable is influenced by the ability of the surrounding environment to dissipate heat from the cable. Seawater can easily dissipate heat; however, laying the cable directly in seawater would leave the cable susceptible to a number of risks. To minimise these risks, the cable is normally protected, and therefore, the surrounding environment is determined by the cable protection method. A cable risk assessment will consider a number of factors, including: seabed type, seabed mobility, fishing risk and shipping anchors. Comprehensive guides to cable risk assessment procedures are available in [27-29].

Cable burial is by far the most common protection method in offshore wind farms (OWFs) and may be stipulated in some regions, e.g., in Germany, the minimum burial depth of OWF export cables is $1.5 \mathrm{~m}$ [27]. A standard burial depth of cables in OWFs is around $1 \mathrm{~m}$, but any value may be agreed between the developer and the supply chain partner; values range from $0.5-3 \mathrm{~m}[22,23]$. However, the conditions in MRE environments may make this difficult as they are generally characterised by a rocky seabed, with little sediment for burying the cable. This is evident in the selection of cable protection measures used in the real-world projects described in Section 2.2. Furthermore, the Sound of Islay demonstration project proposes to surface lay cables and protect with concrete mattresses [30], while the Wave Hub test and demonstration site utilises rock dumping as an external cable protection [31]. 


\subsubsection{Cost Data}

The cost of offshore static cables is given as a unit cost per unit distance. An exponential cost function is defined for offshore static cables [32] and holds true for data collected during this survey:

$$
C_{\text {cable }}=c_{1}+c_{2} \exp \left(c_{3} S\right)
$$

where $S$ is the cable rated power in MVA, $c_{1-3}$ are cost coefficients and $C_{\text {cable }}$ is the offshore static cable cost per unit distance.

Cost data are given in Figure 4a, with cost curve coefficients in Table A1 in Appendix A.

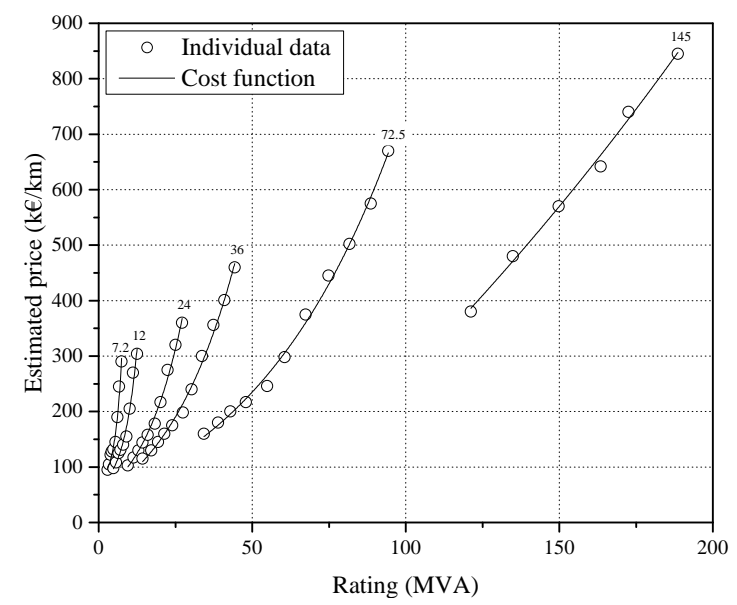

(a)



(b)

Figure 4. Cost data for offshore cables, where the number above each curve is the rated voltage in $\mathrm{kV}$ :

(a) static offshore cable; (b) dynamic offshore cable.

\subsection{Dynamic Cables}

\subsubsection{Functional Description}

Dynamic cables are used in MRE projects to transfer the power generated by floating OECs to the subsea network and may also be required at the transition to stationary structures (such as fixed tidal turbines or surface piercing substations). The main point of difference with static cables is that double layer armouring is considered standard for dynamic cables in order to provide hydrodynamic stability during installation and operation phases.

\subsubsection{Current Status}

Dynamic cables are most prevalent in the O\&G sector, where they have a number of functions: transferring high and low pressure fluid supply, LV and MV power to pumps and other electrical equipment on the seabed, optical communications, etc. [33]. To meet these requirements, they normally have steel tubes or thermoplastic hose fluid conduits, optical fibres and LV or MV voltage electric conductors. These cables are designed with high axial tensile and compressive strengths to maximise conductor fatigue resistance during installation and service [33]. MV power cables with conductor size up to $400 \mathrm{~mm}^{2}$ have been used [33]. Their use has been reported in water depths exceeding $1500 \mathrm{~m}[34]$.

Another application area for dynamic cables is the floating offshore wind industry, which has started to deploy its first projects. As opposed to the fixed counterpart, where all the wind farm elements are fixed, thus only static cables are required, the dynamic cables are essential to a floating wind farm as they transport the electrical power produced at the floating platforms, which are designed for water depths $>50 \mathrm{~m} \mathrm{[35].}$ 
Although still in an early development stage, several demonstration prototypes (1-5 MW) have been installed and pre-commercial parks (>5 MW) are expected to be deployed in 2017/2018 [36]. The demonstration prototypes and pre-commercial parks currently deployed or in construction use free-hanging MV/HV dynamic cables rated from 6-66 kV, with higher export cable voltages (e.g. 110-220 kV) expected to be deployed in commercial wind farms [35,37]. Some examples are provided in Figure 5. To minimize the mechanical loads induced on the cable by the motions and vibrations of the floating platforms, some ancillary elements are commonly used. These are briefly described in Table 2.

Table 2. Dynamic cable ancillary elements.

\begin{tabular}{cc}
\hline Element & Description \\
\hline $\begin{array}{c}\text { Buoyancy } \\
\text { modules }\end{array}$ & $\begin{array}{c}\text { Syntactic foam elements encapsulated in a polyethylene structure that } \\
\text { are distributed along sections of the dynamic cable to provide floating } \\
\text { assistance. They decouple the floating platform motions from the } \\
\text { touchdown point, while at the same time reduce the hang-off loads on } \\
\text { the cable clamp on the platform. They are typically installed in a } \\
\text { 'lazy-wave' configuration. }\end{array}$ \\
$\begin{array}{c}\text { Bend } \\
\text { stiffeners }\end{array}$ & $\begin{array}{c}\text { Cone-shaped polyurethane elements, installed at the cable's end } \\
\text { transition stiffness to the cable in order to help mitigate the bending } \\
\text { stress caused by the motions of the device. }\end{array}$ \\
\hline $\begin{array}{c}\text { Bend } \\
\text { restrictors }\end{array}$ & $\begin{array}{c}\text { Polyurethane interlocking elements, typically installed at the interface } \\
\text { between flexible and rigid structures, to prevent over-bending. They are } \\
\text { designed to lock at a maximum curve radius when subject to a specified } \\
\text { external load. The bend restrictor is usually the choice when } \\
\text { (quasi-)static loads act on the cable, as opposed to bend stiffeners, which } \\
\text { are more suited for damping dynamic loads. }\end{array}$ \\
\hline $\begin{array}{c}\text { Cable } \\
\text { protectors }\end{array}$ & $\begin{array}{c}\text { Polyurethane half-shell sleeves that are installed at the cable touchdown } \\
\text { point to provide both impact and abrasion resistance. }\end{array}$ \\
\hline
\end{tabular}

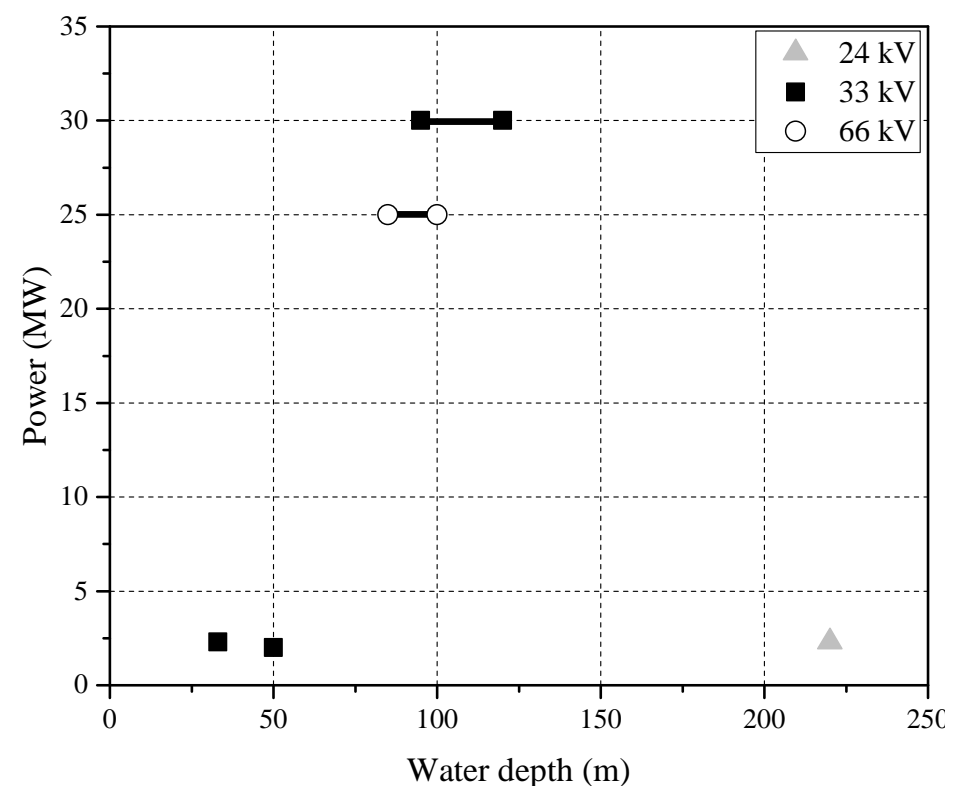

Figure 5. Ratings of dynamic cables used in offshore floating wind. A solid line between two data points indicates the range of water depths for which the cable has been tested. 


\subsubsection{Application in Marine Energy Arrays}

Due to the nature of floating OEC power take-off, they will operate in locations with high wave energy densities. The connected dynamic cable will, therefore, be subject to dynamic and cyclical loading regimes, and the cable manufacturer will require precise details of the installation conditions, the sea state conditions for the site and expected dynamic loads of the combined cable-OEC system during operation.

Installation is one of the most critical phases of the dynamic cable lifecycle, with around half of all failures occurring during this phase [38]. The greatest potential for damage to the dynamic cable will occur during unexpected vessel motions because of adverse weather conditions or when laying needs to be stopped due to an installation equipment failure. This can lead to the cable being in a suspended state for substantial periods, with vessel motions subjecting the cable to continuous bending. However, while these failure modes are relatively well understood, the operational phase of dynamic cables in MRE environment may present a higher risk due to uncertainty in cable-structure interactions.

The forces due to induced motions of the floating OEC may be very different from the forces on dynamic cables used in $O \& G$ platforms or even floating wind platforms. While these platforms are designed to remain as stationary as possible and damp all motions, floating OECs are designed to amplify the induced wave motions in order to maximise power extraction. As such, the cable will have to endure greater forces and stresses due to inherent operating environment and induced motions from the OEC itself.

\subsubsection{Cost Data}

Up to $33 \mathrm{kV}$, the dynamic cable will be approximately 30-50\% more expensive than the equivalent rated static cable. Therefore, the exponential cost function can also be applied for this component (1). Cost data are given in Figure $4 \mathrm{~b}$, with cost curve coefficients in Table A2 in Appendix A. A scale factor of $60-90 \%$ more expensive than the equivalent static cable up to $66 \mathrm{kV}$ has also been provided by a major cable manufacturer.

\section{Connectors}

Connectors allow for a non-permanent connection of different parts of the electrical system, facilitating the recovery of devices and components for maintenance. Connectors are used to connect two cables or a cable to another piece of electrical equipment within marine energy farms. Optical connectors are used to transfer communication signals to pass between the different components in the electrical network. Hybrid connectors include both power and optical contacts. Connectors are classified based on whether they are mated in a dry or wet environment, i.e., above or below the water surface, as dry- and wet-mate connectors. Penetrators, terminators and junction boxes are other connection options available.

\subsection{Dry-Mate Connectors}

\subsubsection{Functional Description}

Dry-mate connectors are deployed under water, but they are mated/de-mated in dry atmosphere. During installation of dry-mate connectors, deck area will be required to make the connection, and vessel lift capability must be able to handle both connector ends and cable/component weight during the operation.

\subsubsection{Current Status}

Dry-mate connectors are not typically found in OWFs, as they are designed such that there is no need to (dis)connect elements of the array, and the turbines are permanent installations, i.e., they are not designed to be recovered to the shore for maintenance. The dimensions of the turbine towers allow 
for connections within the turbine foundation, which are typically terminated at the turbine switchgear. The collection point, i.e., the offshore substation, has always been a surface piercing platform, and the cables will be directly terminated into the switchgear via the on-deck joint box. However, connectors can be used with floating wind turbines.

Floating structures can be more readily recovered to shore for maintenance, reducing exposure to risky and costly offshore procedures. In contrast to fixed structures, these turbines will need a non-permanent system of connection, and given that the operating components of a floating turbine are all above the water line, dry-mate connectors are suitable and may be utilised. Although not used in OWFs, dry-mate connectors are an established technology in the O\&G sector and have been used in a wide range of applications up to a $3000 \mathrm{~m}$ water depth at pressures up to $1000 \mathrm{bar}$. The connectors used in the O\&G sector have traditionally been rated for $L V$ and $M V$, and there are many examples of low power dry-mate connectors with multiple contacts. Connectors with voltage ratings up to $3 \mathrm{kV}$, that have from 2-40 contacts, with each contact rated from between $50 \mathrm{~A}$ and $100 \mathrm{~A}$, are commercially available and have widely been used [39-42].

Figure 6a shows a selection of dry-mate connectors, at the power and voltage levels expected be seen in MRE arrays. Most of these connectors come with a design life of 25-30 years and list a minimum life of 100 mate/de-mate cycles. Furthermore, many of these manufacturers also have a range of hybrid connectors that facilitate connection of optical fibre communication cables along with power cables.

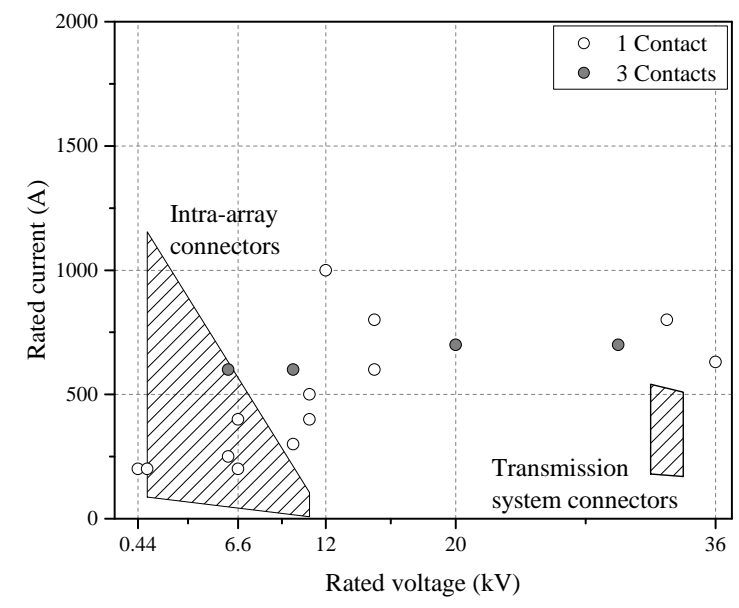

(a)

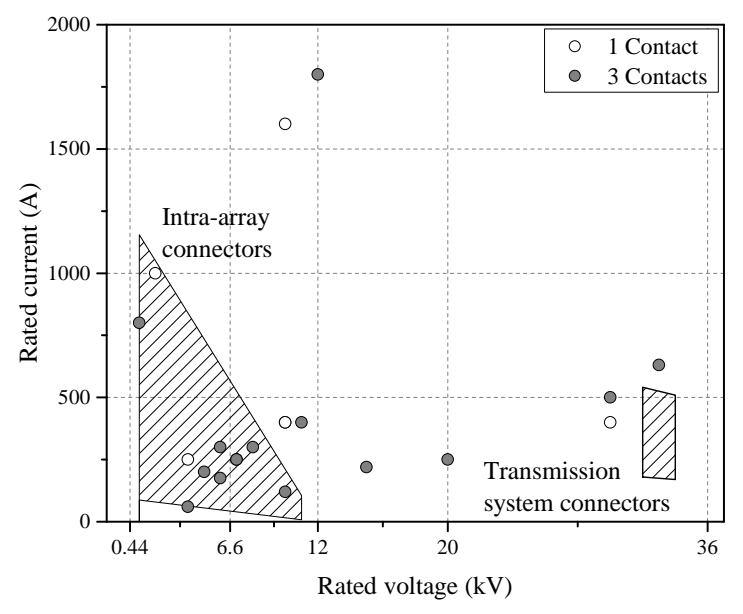

(b)

Figure 6. Examples of available connectors, where the shaded region indicates the expected requirements of device-array and array-transmission connectors: (a) dry-mate connectors (b) wet-mate connectors.

\subsubsection{Application in Marine Energy Arrays}

Many companies that have traditionally served the O\&G sector have also started developing products for the MRE sector. This technology transfer will allow for rapid development of connectors for the MRE sector. The electrical specifications of connectors for the O\&G industry, developed at LV and $\mathrm{MV}$, are comparable to the needs of the MRE sector. Indeed, an industry requirement of connectors rated at $0.15-2.0 \mathrm{MW}$ (at 1-11 kV) for the intra-array cable and between 10 and $30 \mathrm{MW}$ at $33 \mathrm{kV}$ for the export cable is proposed in [43]. Although these technical requirements were issued for wet-mate connector systems, these are equally valid for dry-mate connectors. Advances in floating offshore wind farms will also drive technological development in this operating region.

Specific examples of dry-mate connectors currently utilised in the MRE sector are shown in Figure 6a. All connectors currently deployed in the MRE sector have three contacts, as this best serves the needs of connecting three core cables. Although not shown in Figure 6a, one of the highest power rated connectors in the market today is rated at $132 \mathrm{kV}$ and $700 \mathrm{~A}$ [44]. This connector, rated at 
160 MVA, has a greater capacity than that required by an MRE array. Similar connectors designed for the $O \& G$ sector have operating specifications that far exceed the needs of the marine energy industry. As discussed in Section 2, MRE farm deployment is expected in water depths up to $200 \mathrm{~m}$. At such depths, hydrostatic pressure and temperature are not expected to be limiting factors, and cost may be reduced up to $50 \%$ of the equivalent rated connector used in the O\&G sector [45].

However, the cyclical nature of the environment may accelerate component fatigue. For example, a $3 \mathrm{~m}$ tidal range variation in $30 \mathrm{~m}$ of water will cause a 0.7 bar pressure variation [46]. It is important that connectors can withstand the high wave and current loading regimes likely to be encountered, and bend restrictors or stiffeners could be used to limit cable bending at the connector-cable interface. The environment of marine energy sites may also be more conducive to corrosion and marine growth than other sectors, and care should be taken to limit these. The control and mitigation of these will be achieved by maintenance and by selecting appropriate material for the housing. These may be considered as a separate issue to the electrical capability of the component.

\subsubsection{Cost Data}

It is estimated that dry-mate connectors will cost between 100 and $200 \mathrm{k} €$ per connector, although no further information of voltage or current ratings is supplied [47]. However, a major manufacturer of dry-mate connectors suggested that their $30 \mathrm{kV}$ connector would cost approximately $70 \mathrm{k} €$. A maximum of $15 \%$ discount can be expected on the cost of connectors when a large quantity is purchased [43].

\subsection{Wet-Mate Connectors}

\subsubsection{Functional Description}

Wet-mate connectors are both deployed and mated/de-mated under water. They are used to link offshore marine devices to cables and other equipment, which is difficult in the challenging environmental conditions offshore. Wet-mate connectors can be mated/de-mated, depending on environmental conditions, using ROVs, by divers or using stab-plates [43].

\subsubsection{Current Status}

Wet-mate connectors, mainly rated at less than $12 \mathrm{kV}$ and without fibre optic connection systems, have extensively been used in the $O \& G$ sector [43]. At higher voltages $(>12 \mathrm{kV})$, there are fewer options. The range of voltage and current ratings of currently available wet-mate connectors is shown in Figure $6 \mathrm{~b}$. Most of these connectors have been pressure compensated for operation at very high pressures, seen at depths of up to $3000 \mathrm{~m}$, as experienced in deep water O\&G exploration and production. At such depths, the water temperature is almost constant at $4{ }^{\circ} \mathrm{C}$ and does not significantly affect the life and reliability of these connectors. ROV mateable connectors have been the preferred solution at these depths.

\subsubsection{Application in Marine Energy Arrays}

The emergence of the offshore renewables industry over the past few years has seen most wet-mate connector manufacturers extend their product range to cater to it. Some manufacturers have developed wet-mate connectors that have been designed especially for the renewable application and can be only used up to depths of $100 \mathrm{~m}$. Figure $6 \mathrm{~b}$ shows currently available (commercially available, under development and under testing) wet-mate connectors that can be used in the offshore renewables sector. There are plenty of wet-mate connectors available to meet the intra-array network connection requirements of wave and tidal devices currently being tested.

The same cannot be said about wet-mate connectors for the export cable connection. There are only three manufacturers commercially producing/developing $33 \mathrm{kV}$ high power wet-mate connectors. Considering that the export cable connection need not be mated/de-mated as many times as the 
intra-array network connections, this may be less critical for furthering the advances in the offshore renewables industry.

Offshore marine farms are anticipated to be situated at shallower water depths (up to $200 \mathrm{~m}$ ) where there would be a higher degree of corrosion and marine growth. These will have to be mitigated through proper material selection and/or by applying coatings [48]. Even at these shallow water depths, due to the effects of wave and current loadings that the connector will need to endure during installation and operation, these connectors will need to be ROV mateable. Having divers do the mating/de-mating operations will be very sensitive to weather windows and health and safety requirements. Like dry-mate connectors, manufacturers expect wet-mate connector lifetime to be between 20 and 30 years, which is sufficient for marine energy projects [43]. Furthermore, the rated maximum number of mating/de-mating cycles is between 50 and 150, based on the connection system being used [43].

\subsubsection{Cost Data}

As wet-mate connectors are a relatively new technology in the renewable energy sector, there is limited cost information available. Low-spec connectors may cost as little as $20 \mathrm{k} £ /$ unit [43], but these are not suitable for use in MRE arrays. For the ratings required in MRE arrays, two major manufacturers informed that their wet-mate connectors would be $100 \mathrm{k} £$ or 2-3-times more expensive than their dry-mate counterparts. As shown in Figure 7, a major manufacturer estimates a future price of between 100 and $250 \mathrm{k} £ /$ unit, accounting for learning rates and economies of scale [49,50]. This aligns with other estimates of wet-mate connector cost between 150 and $250 \mathrm{k} €$ per connector [47]. However, based on manufacturer data in Figure 7, it is worth emphasising that this is a projected cost, and the current cost estimate can be up to three to seven-times higher.



Figure 7. Connector cost data. The filled box is the dry-mate in $€[47]$; the grey box is the wet-mate in $€$ [47]; the black line is the wet-mate in $£$ from [49]; and the dashed line is the wet-mate in $£$ from [50].

\subsection{Comparison of Wet- and Dry-Mate Connectors}

Connectors will be a key component of the electrical architecture of MRE arrays. They provide fast deployment and recovery of components and can help to reduce installation and O\&M costs, which are predicted to be between $33 \%$ and $50 \%$ of total project costs [51]. Compared to wet-mate connectors, dry-mate connectors are a more mature technology and are available at higher currents and voltages and lower unit cost [9]. Accordingly, dry-mate connectors are currently very much the norm for connecting devices. Indeed, one major manufacturer does not consider wet-mate connectors 
a viable option for array-scale development at this time [13]. However, MeyGen Phase 1a makes some use of wet-mate connectors, and any operational advantages that are observed during this deployment may help wet-mate connectors become the preferred method of connection in future arrays.

With dry-mate connectors, additional cable length is required on either side of the connector to allow for re-floating operations during mating/de-mating procedures. This extra cable length can be between two- and three-times the sea depth at the location $[9,43,52]$. Managing such lengths of subsea cable is challenging, especially in deeper or more volatile waters, where concrete mattresses may need to be positioned over the extended lengths of exposed cables to reduce their motion due to tidal currents [43]. These additional costs, and the increased requirements on installation and O\&M vessel specification, must be considered against the higher capital cost of wet-mate connectors.

In practice, many marine energy farm equipment manufacturers and developers envisage a mix of dry and wet-mate connectors within the farm [11,12,43]. There is some consensus that wet-mate connectors will be used in parts of the array where many mating/de-mating operations are expected, i.e., the connection points for the OECs to the subsea network, with dry-mate connectors used for connections to the collection point and the export cables [11,12].

\section{Transformers}

In offshore networks, transformers are used for a large number of functions; the component classification in Table 1 presents four transformer categories. However, the largest and most expensive are the power transformers used to step-up the voltage to minimise power losses in the transmission back to shore. Accordingly, this paper considers power transformers in most detail and categorises them based on their operating environment. Some additional considerations of transformers in offshore collection points are discussed further in Section 8.

\subsection{Dry-Environment Transformer}

\subsubsection{Functional Description}

Transformers are widely used within onshore and offshore electrical networks. The primary and secondary voltage and rated power will be determined as part of the overall electrical architecture design process. The other main electrical consideration of transformer design is the insulation material. Due to the harmful nature of some insulation materials, this choice is of particular interest in offshore applications, which may be located in environmentally sensitive areas. Based on the type of insulation, each transformer category can be further divided into liquid-filled or dry-type.

\subsubsection{Current Status}

Traditional liquid-filled transformers use oil as the insulation and cooling medium. Although this is an established method, there are environmental and safety concerns about using this flammable substance. Offshore guidelines suggest that liquid-cooled transformers need to be hermetically sealed and that the cooling medium should not be toxic [53]; where possible, air-cooled dry-type transformers are the preferred technology [53,54]. Furthermore, the Institution of Electrical Engineers (IEE, now the Institution of Engineering and Technology (IET)) offshore regulations explicitly forbid the use of oil-filled transformers, deeming this a potential fire risk $[55,56]$.

This is evident in technological trends in the OWF sector, which have used both liquid and dry-type transformers. Historically, dry-type transformers have been prevalent due to their compact dimensions and reduced fire risk. However, liquid filled transformers are more efficient and reliable [57]. As such, there is significant research into alternative, non-flammable transformer insulating fluids, e.g., [58]. These have been demonstrated in MV:HV transformers [59] for the specific application of lightweight offshore substation modules. Wind turbines typically operate between 0.69 and $33 \mathrm{kV}$. ABB offer a rating of 9.7 MVA at this voltage level, which is to be installed in 
8-W offshore wind turbines [60]. There is also interest to operate wind farms with a 66-kV intra-array voltage level [24], and turbine transformers are available for this purpose [61].

\subsubsection{Application in Marine Energy Arrays}

In the MRE sector, dry-environment transformers will only be required on surface piercing collection points. As such, their application is discussed further in Section 8.

\subsubsection{Cost Data}

Transformer cost will be determined by the voltage transformation and MVA rating of the unit. A power function, (2), was proposed in [32], which holds for data collected in this survey. However, the higher rated voltages have a linear relationship with power. Examples of dry environment transformer unit costs are given in Figure 8, based on data obtained from [62]. An oil-type transformer is typically 1.3-times the price of a dry-type transformer [63].

$$
C_{\text {transformer }}=c_{1} S^{c_{2}}+c_{3}
$$

where $S$ is rating of the transformer in MVA, $c_{1-3}$ are cost coefficients and $C_{\text {transformer }}$ is the transformer unit cost. Coefficients values are given in Table A3 in Appendix A.

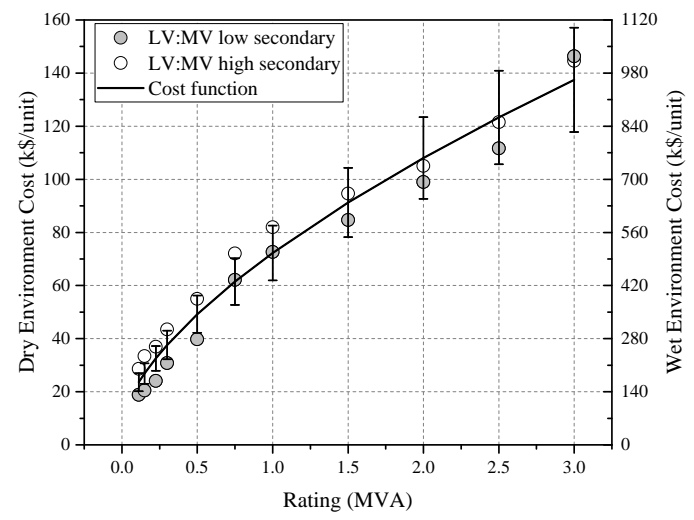

(a)

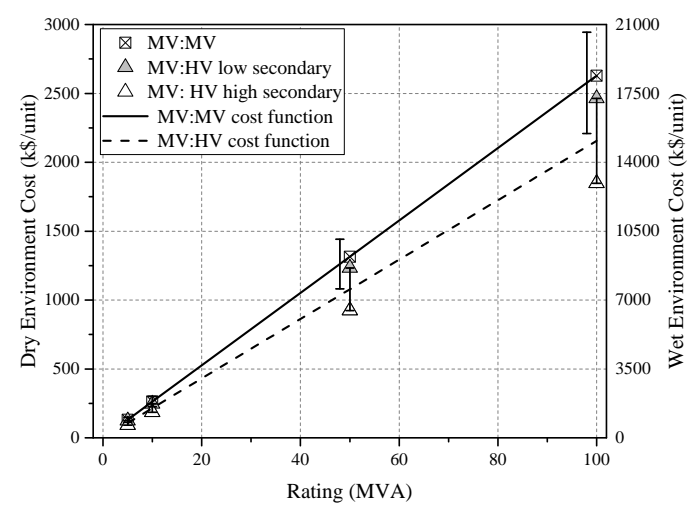

(b)

Figure 8. Dry-type transformer cost data: (a) OEC transformer; (b) collection point transformer; where division into OEC and collection point transformer is based on an arbitrary maximum OEC power of $3 \mathrm{MW}$. The error bars indicate the possible range of wet-transformer cost

For the LV:MV transformers shown in Figure 8a, the transformer with higher rated secondary will be between $40 \%$ and $60 \%$ more expensive for lower rated powers, although this difference reduces for larger rated units. This is consistent with general advice available in literature, e.g., it is stated that LV: $66 \mathrm{kV}$ wind turbine transformers are about $40-50 \%$ more expensive than LV: $33 \mathrm{kV}$ transformers [24]. Conversely, for the MV:HV transformers shown in Figure 8b, the transformer with the higher rated secondary will be $25 \%$ cheaper.

\subsection{Wet-Environment Transformer}

\subsubsection{Functional Description}

The function of the subsea transformer is identical to a standard power transformer, it is only the operating environment that changes. The general development process for a subsea transformer is as follows:

1. A dry-type topside transformer is designed and developed for a project; 
2. The transformer is placed in a water-tight and liquid-filled container. The liquid is pressure compensated with the outside water pressure to ensure that the system does not collapse when placed under water.

\subsubsection{Current Status}

The first subsea transformer, rated at $750 \mathrm{kVA} 10.5 / 3.5 \mathrm{kV}$, has been in operation since 1998 at a depth of around $1000 \mathrm{~m}$ [64]. This has progressed with two operational subsea transformers, rated at $1.6 \mathrm{MVA} 11 \mathrm{kV} / 1 \mathrm{kV}$, in operation since 1999 at a depth of $500 \mathrm{~m}$ [65]. Since then, there have been incrementally larger units developed with recent designs ranging from 5-20 MVA [66] up to 70 MVA [67]. Some recent designs, rated at $3 \mathrm{MVA}, 6.6: 22 \mathrm{kV}$ and qualified up to $3000 \mathrm{~m}$, utilise a biodegradable and environmentally friendly cooling liquid instead of oil $[64,68]$. An overview of operational subsea transformers is provided in Figure 9.

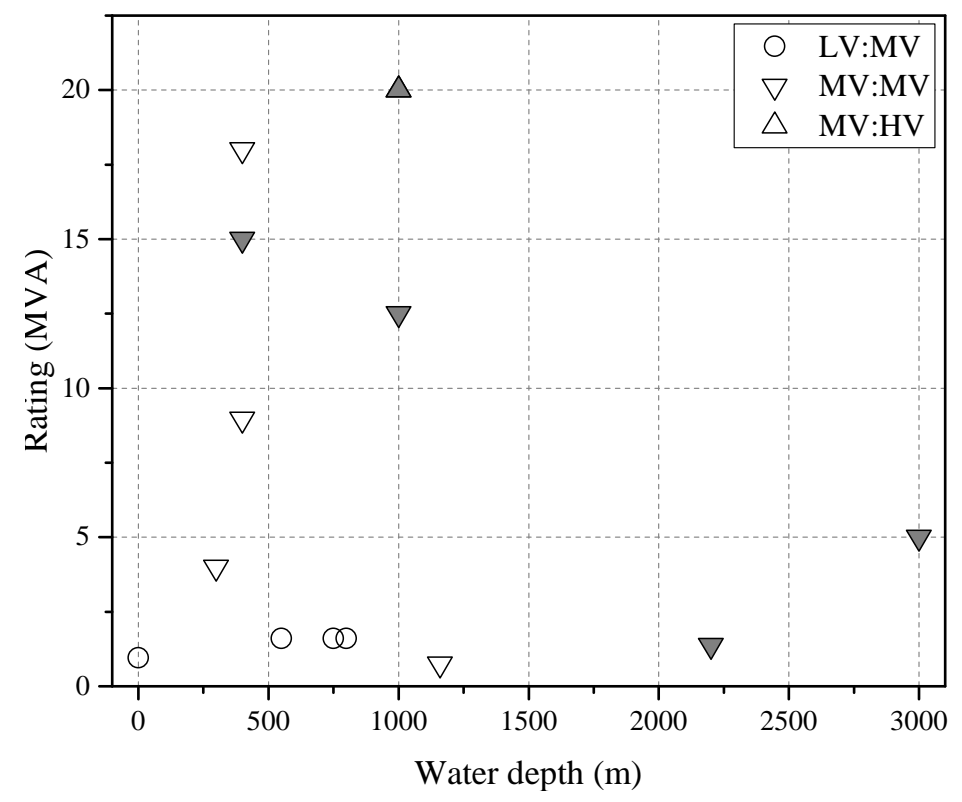

Figure 9. Examples of wet-environment transformers, where grey symbols represent test units and white symbols represent units in commercial activity.

\subsubsection{Application in Marine Energy Arrays}

One concern of the use of subsea components specific to the MRE sector is the possibility of marine growth on cooling conduits, which may reduce the ability to dissipate heat to the surrounding environment. A typical transformer's environmental temperature design range can be from $-20-+40{ }^{\circ} \mathrm{C}$, with the average 24 -h temperature not exceeding $30^{\circ} \mathrm{C}$ and the average annual temperature less than $20^{\circ} \mathrm{C}$ [69,70]. In subsea operation, cooling is provided by natural convection with the seawater, but similar temperature requirements would be considered. Several manufacturers have extensive experience of designing transformers to operate in extreme conditions, including the corrosive salt spray environment encountered offshore. Examples from the MRE sector include the $950 \mathrm{kVA}$ step-up 0.69:11/33 kV transformer in the Pelamis device. One tidal turbine design concept includes a 0.69:6.6 kV transformer in the nacelle [19].

When operating in this environment, motion must be carefully considered, as vibrations can adversely affect electrical equipment. There are several technical standards that define vibration and shock tests commonly used to design and test equipment in the OWF industry, e.g., IEC 60068 [71]. Installation conditions will be specified by the manufacturer and should be considered when selecting the vessel to avoid excessive movement. 


\subsubsection{Cost Data}

Based on conversations with major transformer manufacturers, subsea transformers are tailored for each project and thus are not yet commercially available off-the-shelf. Although actual costs for subsea transformers are not readily available, a major manufacturer provided a scale factor of six- to eight-times to convert the cost of dry-type topside transformers into a reasonable approximation of subsea transformer costs.

Accordingly, a power function is again utilised to express the relationship between transformer rating and cost (2). In Figure 8, the mean scale factor value, i.e., seven, is shown. The error bars show the upper and lower boundary of six- and eight-times the cost function. Coefficients are given in Table A3. No other cost data for subsea transformers was identified in the literature.

\section{Switchgear}

\subsection{Functional Description}

Switchgear is a general term used in electric power systems that includes switching devices such as electromechanical disconnect switches, circuit breakers (CB) and fuses to isolate, protect and control electrical circuits and equipment. During normal operation, the switchgear can redirect power flow and permit generators to (dis)connect from the power system. Under abnormal conditions, such as during short circuits where high currents are present, the switchgear can detect faulty conditions and disconnect the unhealthy section from the system. They also provide isolation during installation and maintenance activities, playing a critical role in increasing power system reliability, safety and security. Switchgear components are classified by: voltage, current and interrupt rating, insulation type, operating method, application and purpose. By using these classifications, equipment manufactures can design a proper system according to its intended application.

\subsection{Current Status}

The key component in switchgear are disconnect switches or CBs. LV, low power CBs, used in domestic and commercial applications, operate on thermal or thermal-magnetic principle. However, in MV and HV applications, an arc is produced any time an electrical circuit is interrupted. The arc must be extinguished to ensure current flow is completely depleted. When a short circuit occurs, high currents can flow into a circuit before it is opened by the switchgear. The size and construction of MV and HV CBs are different due to the insulation requirement and arc-extinction process. HV CBs are generally classified further based on the medium used to extinguish the arc, such as vacuum, air-blast and sulphur hexafluoride $\left(\mathrm{SF}_{6}\right)$.

In $\mathrm{HV}$ and high power applications, $\mathrm{SF}_{6}$ gas-filled $\mathrm{CBs}$ are very popular and have widely been used for arc-extinction since the 1980s. $\mathrm{SF}_{6}$ is an inert gas with excellent insulating properties. $\mathrm{SF}_{6}$ maintains its thermal and chemical characteristics for a long time, which makes it highly reliable for $\mathrm{CB}$ applications. A gas blast applied to the arc must be able to cool it rapidly so that gas temperature between the contacts is reduced from $20,000 \mathrm{~K}$ to less than $2000 \mathrm{~K}$ in a few hundred microseconds, so that it is able to withstand the transient recovery voltage that is applied across the contacts after current interruption.

Typically, the switchgears utilised in OWFs are gas-insulated. Several manufacturers provide self-contained solutions for offshore wind applications, with an emphasis on compact and modular structures for easy installation within turbine foundations [72-74]. Switchgears with voltage rating, current rating and breaking capacity of $40.5 \mathrm{kV}, 2.0 \mathrm{kA}$ and $31.5 \mathrm{kA}$ respectively have been realised for installation in turbines (for example in the Greater Gabbard offshore wind farm, U.K. [75]). Switchgears housed on fixed platform substations with voltage rating, current rating and breaking capacity of $245 \mathrm{kV}, 4 \mathrm{kA}$ and $50 \mathrm{kA}$ respectively have been realised (for example at the Gemini offshore wind farm, Belgium [76,77]). Switchgears rated up to $550 \mathrm{kV}, 5 \mathrm{kA}$ and $63 \mathrm{kA}$ are commercially available [74]. 
The OWF industry and O\&G exploration facilities are paying more attention to under-water switchgear systems closer to the subsea load center, as it reduces operational expenditure and the cost of power lines. Consequently, various fault current limiting technologies have also been studied in the literature for subsea switchgear systems [78]. Recent advances in seabed installations provide efficient and economical subsea-to-beach solution for challenging environments like deep-sea and the Arctic, which also eliminates the need for floating production units. Subsea switchgear components have similar operating principles and characteristics except that they are housed inside high pressure withstanding containers suitable for under-water (e.g., at the seabed depth of 1000-3000-m) operation for a long time (e.g., $>30$ years) $[79,80]$.

The current technology used in subsea applications is mostly a magnetically-actuated vacuum quenched switch or a $\mathrm{CB}$ chamber filled with $\mathrm{SF}_{6}$ gas. The $\mathrm{CB}$ typically consists of capacitors that provide momentary power during outage conditions, control modules with sensors to detect faults and provide appropriate signals for proper operation, etc., supervisory control and data acquisition (SCADA) systems are typically employed for remote system control. This is especially important for subsea applications. In recognition of the importance of this emerging market, the IEEE standards association is actively developing the Subsea Electrical Power Standardisation (SEPS) under the base standard code IEEE 67886.

\subsection{Application in Marine Energy Arrays}

Essentially, the role of the switchgear within a marine energy array will be similar to the role of the switchgear in offshore wind farms. Considering that the power ratings of OEC farms in the near to medium term would be much smaller than offshore wind farms, the availability of a switchgear of appropriate ratings will not be an issue for OEC farms, as exemplified by the examples given earlier in the preceding section. However, differences may exist in protection coordination schemes, which are well established for OWFs. Generally, these are divided into protection zones, which reflect the radial network structure: generator, feeder, busbar, transmission transformer. Selectivity is important to ensure that only faulted parts of the network are tripped, isolating the minimum area required for safe operation. At the time of writing, as it is unclear how MRE arrays will be formed, it is hard to predict protection coordination schemes. In the Wave Hub and EMEC demonstration sites, all switchgear are located onshore.

\subsection{Cost Data}

Previous research has identified a linear linear relationship between switchgear cost and voltage rating (3) [32]. Cost coefficients are given in Table A4.

$$
C_{\text {switchgear }}=c_{1} V+c_{2}
$$

where $V$ is rated phase voltage in $V, c_{1-2}$ are cost coefficients and $C_{\text {switchgear }}$ is the switchgear unit cost.

\section{Power Quality}

Prior to the connection to the wider onshore electrical network, offshore energy arrays will have to demonstrate grid code compliance. Grid codes are designed to support connection and use of electricity networks, whilst simultaneously ensuring quality and security of supply. Flexible AC transmission system (FACTS) devices are of particular interest in the context of grid integration of large offshore energy arrays as they can help to ensure grid code compliance.

\subsection{Functional Description}

There are a number of different devices which can be applied, and this is project specific. However, the static VAR compensator (SVC) and the static synchronous compensator (STATCOM) are the most widely-utilised FACTS devices today. Series-connected FACTS devices such as the static synchronous 
series compensator (SSSC) could theoretically have beneficial application, as well; however, they are of less interest than the shunt connected devices identified above. This is because the services offered by series connected devices make them better suited to deployment on the wider transmission network rather than on the generation side. This is in contrast to shunt-connected devices, which are well suited for use at load and generation buses such as the PCC of wind plants. The high cost of series connected devices like the SSSC also makes it hard to justify their use in many cases.

Both SVCs and STATCOMs are shunt connected devices capable of absorbing and generating reactive power. The SVC is typically made up of a thyristor switched capacitance (TSC) in parallel with a thyristor switched reactance (TSR) or thyristor controlled reactance. A STATCOM consists of a self-commutating inverter with a capacitor on the DC side. The inverter is usually built using insulated gate bipolar transistors (IGBTs) that can be switched on and off in a controlled fashion. As a result, the STATCOM has a faster response and wider bandwidth than the SVC. The maximum reactive current injection of the STATCOM is also independent of the terminal voltage. This leads to better voltage support and improved transient stability margins. This means that the STATCOM is more effective than the SVC for improving low-voltage ride-through. Despite the superior characteristics of the STATCOM, SVCs provide a lower cost solution and may, therefore, be favoured in certain applications.

In certain cases, static compensation units may be used in combination with the dynamic compensation offered by FACTS devices. The static compensation, which usually consists of mechanically-switched capacitors and reactors, is good for second to minute responses and is used to shift the dynamic reactive capability towards a lagging or leading value as required. Switched reactors can be used to compensate for the cable capacitance, and such static compensation can significantly reduce the requirement from dynamic compensation units, which are usually costlier.

\subsection{Current Status}

The functionality and benefits offered by FACTS devices like the SVC and STACOM are well understood by the power system community, and they have been widely used in the wind sector to ensure compliance with stringent grid code requirements. A number of solutions is available from major manufacturers. To date, SVC and STATCOM devices have mainly been used to perform the following functions in the wind industry:

- $\quad$ Reactive power support

- $\quad$ Providing fault ride-though (FRT) capability

- Voltage control at PCC

- Power quality control (Flicker, Harmonics, power factor correction)

Some application examples from OWFs are included in Table 3.

Table 3. Examples of FACTS devices employed in the wind sector. PCC, point of common coupling; OWF, offshore wind farm; SVC, static VAR compensator; FRT, fault ride-though.

\begin{tabular}{|c|c|c|c|c|c|c|}
\hline \multicolumn{3}{|c|}{ Project } & \multicolumn{2}{|c|}{ FACTS Device } & \multirow{2}{*}{ Application } & \multirow{2}{*}{ Ref. } \\
\hline Name & Location & MW & Device & Ratings & & \\
\hline Fallago Rig & U.K. & 144 & DSTATCOM & $60 \mathrm{MVAr}$ & $\begin{array}{l}\text { Reactive power support } \\
\text { Voltage control at PCC }\end{array}$ & [81] \\
\hline Nysted OWF & Denmark & 165.6 & SVC & $132 \mathrm{kV}$ & $\begin{array}{c}\text { FRT capability } \\
\text { Voltage control at PCC }\end{array}$ & \\
\hline Thanet OWF & U.K. & 300 & SVC Plus & - & $\begin{array}{c}\text { FRT capability } \\
\text { Reactive power support }\end{array}$ & {$[82,83]$} \\
\hline Greater Gabbard & U.K. & 504 & SVC Plus & - & $\begin{array}{l}\text { Power factor correction } \\
\text { Flicker mitigation }\end{array}$ & [82-84] \\
\hline Whitelee & U.K. & 539 & STATCOM & $\begin{array}{c} \pm 15 \mathrm{MVAr} \\
33 \mathrm{kV}\end{array}$ & $\begin{array}{l}\text { Reactive power support } \\
\text { FRT capability }\end{array}$ & [85] \\
\hline
\end{tabular}

DSTATCOM $=$ Distributed STATCOM. 


\subsection{Application in Marine Energy Arrays}

As array sizes grow and marine energy farms connect into the higher voltage sub-transmission and transmission networks, grid code requirements will become more stringent. It is unlikely that these farms will be able to connect to the grid and comply with the relevant grid codes. FACTS devices will be called upon to perform many of the same functions as those already being performed in the wind industry.

Due to the nature of shunt connected FACTS devices and the functions they perform, it is desirable to connect them at or as close as possible to the PCC, i.e., they are always onshore and usually in the onshore substation. Therefore, it is unlikely that any adaptations related to locating the devices offshore will be necessary. As a result, these same devices could easily be applied in MRE arrays.

Combining devices with energy storage is a development that would improve capability. Some manufacturers already offer such products. The ability to provide active, as well as reactive power support may make such devices more appealing to electric service providers [86]. This could be particularly useful in the context of ocean energy farms because many of these farms are likely to be connected to the lower voltage sub-transmission and distribution networks where the ratios of line reactance to resistance $(\mathrm{X} / \mathrm{R}$ ratio) are much lower (typically less than 0.5 [87]). In these situations, the deviations in voltage due to unit changes in reactive power are small. This means reactive power control for voltage regulation is less effective and not very efficient. As a result, it may be necessary to curtail active power output at certain times or to restrict the amount of generation that can be connected to these networks to ensure that voltage limits are not violated. The use of energy storage, in combination with a FACTS device such as the STATCOM, could alleviate the need to curtail generation and allow more generation to be connected without carrying out expensive network upgrades. This could have wide reaching financial implications as it could reduce the cost of obtaining a grid connection and increase revenue once the farm is connected.

Adding energy storage to a STATCOM can also significantly improve the oscillation damping [86]. With no energy storage, the STATCOM takes two seconds to achieve constant voltage, whereas the STATCOM plus energy storage is able to achieve constant voltage within $0.5 \mathrm{~s}$. A large OEC farm may also introduce an unacceptable level of flicker into the local power system. Installing a combined FACTS device with energy storage near the OEC farm is one solution to resolve flicker [88]. The most stringent limits for flicker require an energy storage time constant of three seconds [89]. The STATCOM plus energy storage is able to exceed this requirement, and its performance is superior to the STATCOM alone [86].

\subsection{Cost Data}

Some guidance is available in literature on FACTS costs, with raw component costs taken from $[90,91]$. The cost can be represented by a second order polynomial (4). Coefficients are given in Table A5, with values presented in Figure 10.

$$
C_{F A C T S}=c_{1} Q^{2}+c_{2} Q+c_{3}
$$

where $Q$ is the rated reactive power in MVAr, $c_{1-3}$ are cost coefficients and $C_{F A C T S}$ is the component unit cost. 


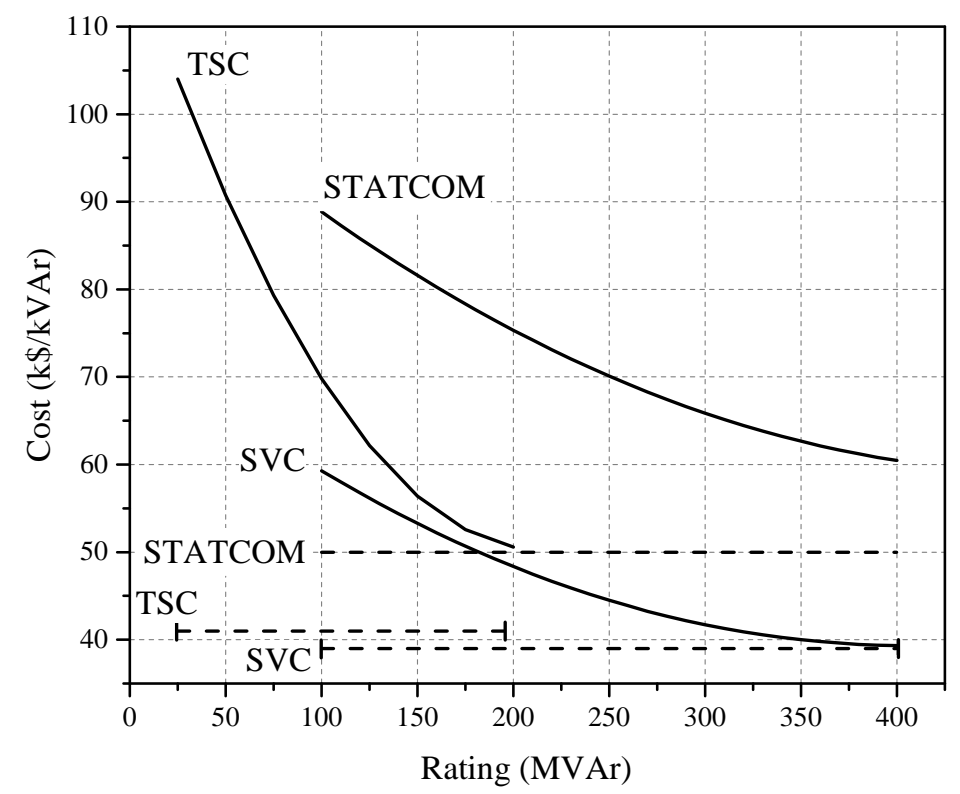

Figure 10. FACTS device cost data. Black line data from [91], black dashed data from [90]. Note: thyristor switched capacitance (TSC) and SVC from [90] both stated as $40 \mathrm{k} \$ / \mathrm{kVAr}$, but value offset for readability purposes.

\section{Collection Points}

Offshore collection points are used to support the transmission of power generated offshore to the onshore grid connection. The functional requirement of the offshore collection point is determined by the project specification; particularly, the OEC operating voltage, the length of the transmission cable and the installed capacity of the array.

\subsection{Functional Description}

The purpose of the offshore collection point is to collect the power from the intra-array cables from a number of devices or clusters of devices and then transmit the power to shore, possibly at a higher voltage level. This design concept is required as the distance to shore and installed capacity of the farm increase. As illustrated in Figure 1, the main components that may be present within a traditional offshore collection point subsystem are: transformer, switchgear and reactive compensation, which have been introduced in previous sections. There are many possible variations of this approach, which are defined by the use of different combinations of these components and the operating environment.

\subsection{Current Status}

A number of different solutions can be found in the offshore wind sector and O\&G industry. In OWFs, an offshore, fixed platform substation design is prevalent. Although the main purpose of the offshore substation is to transform to higher voltage for transmission to shore, there are several other important features that are commonly included in the design, e.g., switching functionality to connect/disconnect equipment and house protection equipment, monitoring/SCADA devices, harmonic filters and reactive compensation to ensure safe operation of the array and achieve grid code compliance.

The variations between offshore platforms are relatively subtle and will tend to be a result of transformer selection. The main design choices to be made are the selection of export voltage level and the number and winding configuration of the transformers. Export voltage in OWFs is typically between 110 and $220 \mathrm{kV}$. For installed capacities of less than $100 \mathrm{MW}$, two-winding transformers 
are commonly used [92]; with three-winding transformers employed in larger installations [93,94]. Although the number of transformers will be at the discretion of the developer, this may be governed by design guidelines, e.g., U.K. grid codes stipulate that all offshore power park modules (i.e., a group of intermittent renewable generators) with installed capacity greater than $90 \mathrm{MW}$ should be able to supply up to $50 \%$ of the installed capacity for an N-1 contingency event [95]. A cost-benefit analysis study of transmission options for offshore wind farms observed that solutions with two substation transformers was more economical for farm sizes greater than 120 MW [93].

Incorporating one or two transformers on a single offshore platform results in large dimensioned top-side structures, which require substantial foundations. Weights of modern offshore substations range between several hundred to several thousand tonnes. The significant civil works and offshore logistics operations associated with such developments require vast amounts of time and capital, and there is interest in the offshore wind community to consider alternative solutions. Incorporating smaller and lighter designs will allow installation by the foundation/turbine installation vessels. It is even possible to integrate the transmission transformer with a turbine foundation [59]. Other novel solutions include the floating substations being developed as part of floating offshore wind farms [96]. Offshore platforms are also widely used in the $O \& G$ sector, but with additional components required to drill, extract, process and store (as necessary) oil or natural gas. As a result, these structures are much larger than the platforms used in renewable energy arrays. However, in deep water applications, subsea infrastructure can be utilised, and the $O \& G$ industry was first in developing underwater solutions to supply power to pumps and compressors up to a $3000 \mathrm{~m}$ water depth $[66,80,97]$.

\subsection{Application in Marine Energy Arrays}

The necessity of using fixed, or floating platforms, in OWFs is driven by the long transmission distances and large power transfers. As such, the technologies and design rules applied within the offshore wind industry may not be directly transferable to MRE projects. For example, it is often stated that there is no need for an offshore substation when transmitting less than $100 \mathrm{MW}$ over a distance less than $15 \mathrm{~km}$ at $33 \mathrm{kV}$ [47]. Although commercial scale arrays of this power are not yet on the horizon for MRE projects, the rated voltage of OECs and transmission distance can lie outside these boundaries, and unique, cost-effective solutions must be found. The environmental and visual impact of large platforms close to the shore can also be considered prohibitive to their use in MRE arrays.

Furthermore, the vast majority of OECs have a single connection and cannot naturally form the radial connections, which are predominant in OWFs. In OWFs, ring main units located in the tower are used to daisy chain the turbines together to form radial strings; cables loop in and out of the turbine tower and terminate directly onto a switch. The need to recover OEC devices for maintenance or repair would require two connectors per device to loop the cables in and out. The space required for two connectors would constrain OEC design, and the cost of such a connection system may be prohibitive.

For small, near-shore installations, this is not a big issue as the power generated in the OEC can be transmitted directly from the offshore area to the PCC. It is feasible to have one export cable per device, without utilising an offshore collection point. This is the approach applied for the initial development at MeyGen and is considered an important part of the learning process. However, for larger scale arrays, a large number of export cables is not practically or financially viable. An alternative to the direct connection design concept is to use offshore collection hubs, and it is expected that this technology will be a key enabling technology in the MRE sector. Accordingly, this is one of greatest design challenges for the MRE supply chain, and design flair and novel approaches are required. The Wave Hub collection device is an example of this design concept in operation in the MRE environment [31]. The Wave Hub is a free-flooding, subsea, carbon-steel structure and has terminations for power and fibre optic cables for four devices, with dry-mate connectors used to serve the dynamic cables. There is no additional offshore electrical equipment, with the switchgear located onshore. In comparison with the direct connection design concept, there is a cost savings from reducing the number of export cables. 
However, this will lower the redundancy at an array level, as the power output is susceptible to a single point of failure.

More than one offshore collection hub may be present, depending on the intra-array configuration. This can provide greater protection selectivity, i.e., reducing the number of devices which are disconnected by a fault or maintenance action. By introducing additional hubs, it is possible to form star or 'hub and spoke' networks for larger-scale arrays and these are commonly proposed as a means of connecting OEC devices in large arrays. Some collection point designs, which house converters, switchgears, transformers and different combinations of these components, are effectively subsea substations. Housing these components in (a number of) centralised hubs may provide a cost-effective solution compared to housing power conditioning equipment at each OEC. Such designs have similarities to the seabed process control hubs used to control electrical and hydraulic equipment in the $O \& G$ industry. Although the $O \& G$ sector has led the way in subsea transformer and switchgear development, novel solutions are in development for MRE, with subsea substation design concepts reviewed in [98]. Unlike the solutions common in the O\&G sector, these subsea collection points will typically house all components within one single structure for ease of installation; the structure may be a self-contained, pressure compensated, hermetically-sealed unit $[99,100]$ or may feature several traditional subsea components fixed to a single support structure [11]. On-bottom stability will depend on the seabed type; with solutions ranging from suction piles for soft areas to concrete foundations, gravity-based structures or mud mats for hard seabed areas.

Due to the dimensions of the MV components likely to be used, these subsea collection points will be substantial pieces of equipment, and space limitations may limit the number that may be placed within an MRE array. An alternative is to utilise T-off connectors, allowing OECs to form the string topology commonly used for connecting offshore wind turbines. T-off connectors are essentially sockets consisting of three connectors; one to connect the OEC and two to form a radial chain with T-off connectors of the neighbouring OECs or to the collection point or export cable. Such a system would enable devices to have a single connector, making deployment and recovery easier; offering a cost-effective solution for the MRE industry. The authors are aware of at least two manufacturer offering off-the-shelf products developed specifically for OEC devices that can create T-off connections [101,102]. Other manufacturers have conceptual designs based on existing industrial standard components. However, these have yet to be developed. Examples from literature of all collection point design concepts are included in Table 4.

Table 4. Summary of subsea collection point design examples.

\begin{tabular}{|c|c|c|c|c|c|c|c|c|}
\hline \multicolumn{3}{|c|}{ Components } & \multirow{2}{*}{ Connectors } & \multicolumn{3}{|c|}{ Ratings } & \multirow{2}{*}{$\frac{\text { Water Depth }}{(\mathrm{m})}$} & \multirow{2}{*}{ Ref. } \\
\hline S'gear & Converter & Trafo & & I (A) & $\mathrm{V}(\mathrm{kV})$ & S (MVA) & & \\
\hline$\checkmark$ & - & LV:MV & $10 \times$ Dry-mate & ns & ns & 1.5 & 50 & [99] \\
\hline ns & ns & ns & 4-16 & ns & $\leq 33$ & ns & ns & [103] \\
\hline$\checkmark$ & - & MV:MV & $\begin{array}{l}8 \times \text { Wet-mate }+ \\
2 \times \text { Dry-mate } *\end{array}$ & & $\leq 30$ & 10 & ns & [11] \\
\hline$\checkmark$ & $\checkmark$ & LV:LV & ns & ns & ns & $1.75-10$ & ns & [104] \\
\hline - & - & - & $4 \times$ Dry-mate & ns & $11 / 33$ & 20 & $51-57$ & [31] \\
\hline - & - & - & 2 & 630 & 20 & ns & 100 & [101] \\
\hline- & - & - & Dry & $630-1250$ & $30-36$ & ns & 100 & [102] \\
\hline$\checkmark$ & $\checkmark$ & $\checkmark$ & ns & ns & ns & ns & 1000 & [80] \\
\hline
\end{tabular}

* Wet-mate connectors are used to make internal ring with dry-mate connectors for export; ns = not stated; $\mathrm{S}^{\prime}$ gear $=$ switchgear; Trafo $=$ transformer.

\subsection{Cost Data}

Collection point cost data are summarised in Table 5. As subsea hubs and T-off connectors are emerging technologies, there is very little information available on their cost. Only [9] provides a cost estimate for a T-off connector. 
Table 5. Summary of collection point cost data.

\begin{tabular}{ccccc}
\hline Collection Point Type & Costs Included & Cost & Units & Ref. \\
\hline Fixed & Electrical plant & $120-150$ & $\mathrm{k} € / \mathrm{MW}$ & {$[47]$} \\
\hline \multirow{2}{*}{ Fixed } & Foundation, cable riser, switchgear and auxiliary & 5 & $\mathrm{M} £ / \mathrm{unit}$ \\
& Variable cost & $300-500$ & $\mathrm{k} £ / \mathrm{MW}$ & {$[9]$} \\
\hline \multirow{2}{*}{ Floating } & Foundation, cable riser, switchgear and auxiliary & $1-2$ & $\mathrm{M} £ / \mathrm{unit}$ & {$[9]$} \\
& Variable cost & $300-500$ & $\mathrm{k} £ / \mathrm{MW}$ & {$[9]$} \\
\hline T-off connector & MV transformer to 11 kV & $300-600$ & $\mathrm{k} £ /$ unit & {$[9]$} \\
\hline T-off connector & MV transformer to 33 $\mathrm{kV}$ & $500-800$ & $\mathrm{k} £ /$ unit & {$[9]$} \\
\hline Fixed & Design, manufacture and installation of substation & $133-215$ & $\mathrm{k} £ / \mathrm{MW}$ & {$[105]^{*}$} \\
\hline & * Based on data in original reference. & & &
\end{tabular}

\section{Electrical Component Database}

The data collected during this review are made freely available for use by the community in a database, housed online at [5]. The database has been developed as part of an open source tool that provides an integrated platform for the lifecycle assessment of ocean energy arrays with respect to economic, reliability and environmental performance indicators. Further information of the tool is available at [106].

As such, the database contains additional parameters, which are beyond the scope of techno-economic review presented in this paper, but which are important when selecting components for an offshore ocean energy array. For all components, this includes:

- Electrical parameters: standard electrical engineering parameters, such as voltage and current ratings, which provide the basic information required to correctly select a component for a high level electrical design;

- Mechanical parameters: which describe the physical attributes of the electrical component, such as weight and dimensions, and those which define the interaction with the environment during installation and operation phases, such as operating temperature;

- Cost parameter: the component unit cost, which is required for economic analysis;

- Reliability parameters: the component mean time to failure, which is required for reliability analysis.

Further details of all electrical and mechanical parameter fields included in the database are given in Table 6, with the number of database entries for each component type shown in Figure 11. As component lead times play an important role in installation and O\&M planning, these are included in Table A6 for completeness.

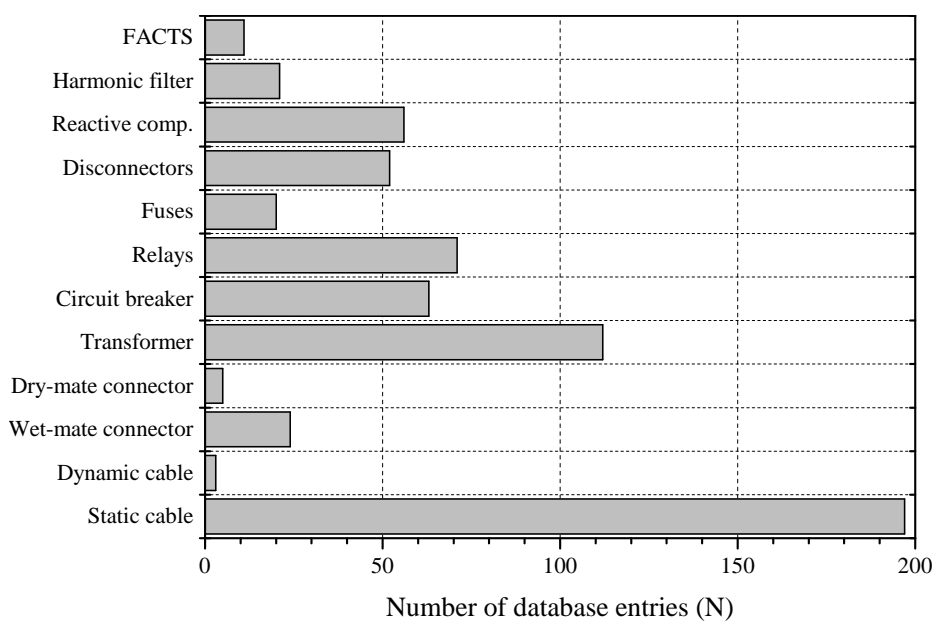

Figure 11. Number of database entries. 
Table 6. Overview of component database electrical and mechanical fields.

\begin{tabular}{|c|c|c|c|c|c|c|}
\hline \multicolumn{2}{|r|}{ Parameter } & \multicolumn{5}{|c|}{ Component Type } \\
\hline Type & Name & Cable & Connector & Transformer & Switchgear & Power Quality \\
\hline \multirow{18}{*}{ Electrical } & Number of conductors & $\checkmark$ & $\checkmark$ & - & - & - \\
\hline & Conductor CSA & $\checkmark$ & $\checkmark$ & - & - & - \\
\hline & Conductor material & $\checkmark$ & - & - & - & - \\
\hline & Insulation material & $\checkmark$ & - & - & - & - \\
\hline & Screen material & $\checkmark$ & - & - & - & - \\
\hline & Armouring material & $\checkmark$ & - & - & - & - \\
\hline & Serving material & $\checkmark$ & - & - & - & - \\
\hline & Rated voltage & $\checkmark$ & $\checkmark$ & $\checkmark$ & - & $\checkmark$ \\
\hline & Secondary voltage level & - & - & $\checkmark$ & - & - \\
\hline & Maximum rated voltage & $\checkmark$ & $\checkmark$ & - & - & - \\
\hline & Impulse level & $\checkmark$ & - & - & - & - \\
\hline & Impedance & $\checkmark$ & $\checkmark$ & $\checkmark$ & - & - \\
\hline & Rated current & $\checkmark$ & $\checkmark$ & $\checkmark$ & - & $\checkmark$ \\
\hline & Making-breaking capacity & - & $\checkmark$ & - & $\checkmark$ & - \\
\hline & Frequency & $\checkmark$ & $\checkmark$ & $\checkmark$ & - & $\checkmark$ \\
\hline & Fibre optic & $\checkmark$ & $\checkmark$ & - & - & - \\
\hline & Windings & - & - & $\checkmark$ & - & - \\
\hline & Control system & - & - & $\checkmark$ & $\checkmark$ & - \\
\hline \multirow{10}{*}{ Mechanical } & Weight & $\checkmark$ & $\checkmark$ & $\checkmark$ & $\checkmark$ & $\checkmark$ \\
\hline & Dimensions & $\checkmark$ & $\checkmark$ & $\checkmark$ & $\checkmark$ & $\checkmark$ \\
\hline & Max. pulling tension & $\checkmark$ & - & - & - & - \\
\hline & Max. bend radius & $\checkmark$ & - & - & - & - \\
\hline & Operation/mating cycles & - & $\checkmark$ & - & $\checkmark$ & $\checkmark$ \\
\hline & (De-)mating force & - & $\checkmark$ & - & $\checkmark$ & - \\
\hline & Maximum water depth & - & $\checkmark$ & $\checkmark$ & $\checkmark$ & $\checkmark$ \\
\hline & Operating temperature & $\checkmark$ & $\checkmark$ & $\checkmark$ & $\checkmark$ & $\checkmark$ \\
\hline & Cooling system & - & - & $\checkmark$ & $\checkmark$ & $\checkmark$ \\
\hline & Outer coating & $\checkmark$ & $\checkmark$ & $\checkmark$ & $\checkmark$ & $\checkmark$ \\
\hline
\end{tabular}

\section{Conclusions}

Electrical components form a key part of an offshore energy array, transmitting the generated power back to shore and facilitating communication with devices and control elements. The electrical infrastructure may form a considerable portion of the project cost, e.g., it is estimated to account for up to $25 \%$ of offshore wind farm capital cost [107], and standardised electrical infrastructure is one of the key drivers in commercialising MRE arrays. As such, understanding the main electrical components, their current capabilities and how they can be deployed in MRE arrays is crucial as the industry aims to progress from single-device demonstration projects to array-scale developments.

To this end, this paper presents an overview of a data collection, which focuses on the needs of the MRE sector. The application of the electrical components within MRE arrays is discussed, and cost data are presented. This consolidates existing literature, providing updated cost information on static cables and guidance on costing dynamic cables and subsea transformers. Additional parameters, which include the main electrical and mechanical parameters, are available in an online database. This ensures that the data collection is compatible not only with load flow analysis and electrical design, but also for assessing logistic phases, i.e., vessel and weather window requirements, which is of particular importance when installing in highly dynamic offshore conditions. This is also important as the capital cost of components should not be considered in isolation, but should ideally be assessed with consideration of the installation, operation and maintenance cost. The open source repository and lifecycle analysis tool are available at [5]. 
Acknowledgments: The authors gratefully acknowledge the contributions of all DTOcean (Optimal Design Tools for Ocean Energy Arrays) project partners for their discussions on database design and during the data collection exercise. This research was supported by the European Commission under the call ENERGY 2013-1 and the United Kingdom Engineering and Physical Sciences Research Council through the SuperGen U.K. Centre for Marine Energy Research. Sandia National Laboratories portion of this work was funded by the U.S. Department of Energy's Wind and Water Power Technologies Office. Sandia National Laboratories is a multi-mission laboratory managed and operated by National Technology and Engineering Solutions of Sandia, LLC., a wholly-owned subsidiary of Honeywell International, Inc., for the U.S. Department of Energy's National Nuclear Security Administration under Contract DE-NA0003525. SAND2017-12562 J.

Author Contributions: All authors were involved in the data collection and preparation process. All authors were involved in the discussion and revision process with section leads as follows: Adam Collin (Sections 1, 5, 8-10), Anup Nambiar (Section 4), David Bould (Section 2), Ben Whitby (Section 7), M. A. Moonem, Benjamin Schenkman and Stanley Atcitty (Section 6) and Paulo Chainho (Section 3).

Conflicts of Interest: The authors declare no conflict of interest.

\section{Appendix A}

Table A1. Static cable cost coefficients.

\begin{tabular}{|c|c|c|c|c|c|c|c|c|}
\hline \multicolumn{2}{|c|}{ Voltage (kV) } & \multicolumn{3}{|c|}{ Cost Coefficient } & \multirow{2}{*}{$\begin{array}{l}\text { Range } \\
\text { (MVA) }\end{array}$} & \multirow{2}{*}{ Units } & \multirow{2}{*}{ Year } & \multirow{2}{*}{ Ref. } \\
\hline Rated & Max & c1 & c2 & c3 & & & & \\
\hline 6.6 & 7.2 & 67.63 & 8.24 & 0.44 & {$[2.9,7.5]$} & $\mathrm{k} € / \mathrm{km}$ & - & - \\
\hline 11 & 12 & 49.37 & 16.32 & 0.22 & {$[4.8,12.5]$} & $\mathrm{k} € / \mathrm{km}$ & - & - \\
\hline 22 & 24 & -1.27 & 50.66 & 0.07 & {$[9.5,27.2]$} & $\mathrm{k} € / \mathrm{km}$ & - & - \\
\hline 33 & 36 & -35.29 & 80.17 & 0.04 & {$[17.0,44.0]$} & $\mathrm{k} € / \mathrm{km}$ & - & - \\
\hline 66 & 72.5 & -57.35 & 105.20 & 0.02 & {$[34.3,94.3]$} & $\mathrm{k} € / \mathrm{km}$ & - & - \\
\hline 132 & 145 & -1337.00 & 1125.00 & $3.5 \times 10^{-3}$ & {$[121.1,188.6]$} & $\mathrm{k} € / \mathrm{km}$ & - & - \\
\hline MV & ns & $0.5-2.0$ & 0 & 0 & ns & $\mathrm{k} £ / \mathrm{m}$ & 2015 & [9] \\
\hline 22 & ns & $0.284 \times 10^{6}$ & $0.583 \times 10^{6}$ & $6.15 \times 10^{-2}$ & {$[10,45]$} & $\mathrm{SEK} / \mathrm{km}$ & 2003 & {$[32]$} \\
\hline 33 & $\mathrm{~ns}$ & $0.411 \times 10^{6}$ & $0.596 \times 10^{6}$ & $4.1 \times 10^{-2}$ & {$[15,67.5]$} & $\mathrm{SEK} / \mathrm{km}$ & 2003 & {$[32]$} \\
\hline 66 & ns & $0.688 \times 10^{6}$ & $0.625 \times 10^{6}$ & $2.05 \times 10^{-2}$ & {$[35,135]$} & $\mathrm{SEK} / \mathrm{km}$ & 2003 & [32] \\
\hline 132 & ns & $1.971 \times 10^{6}$ & $0.209 \times 10^{6}$ & $1.66 \times 10^{-2}$ & {$[100,230]$} & $\mathrm{SEK} / \mathrm{km}$ & 2003 & [32] \\
\hline 220 & ns & $3.181 \times 10^{6}$ & $0.11 \times 10^{6}$ & $1.16 \times 10^{-2}$ & {$[290,385]$} & $\mathrm{SEK} / \mathrm{km}$ & 2003 & [32] \\
\hline MV & ns & $300-800$ & 0 & 0 & ns & $€ / \mathrm{m}$ & ns & {$[47]$} \\
\hline $\mathrm{HV}$ & $\mathrm{ns}$ & 1000-2000 & 0 & 0 & $\mathrm{~ns}$ & $€ / \mathrm{m}$ & $\mathrm{ns}$ & [47] \\
\hline 132 & ns & 7.471 & 39.28 & $1.40 \times 10^{-2}$ & {$[150,189]$ * } & $£ / \mathrm{m}$ & 2008 & [93] \\
\hline 220 & ns & -1044 & 963.4 & $1.91 \times 10^{-3}$ & {$[250,315]$ * } & $£ / \mathrm{m}$ & 2008 & [93] \\
\hline 33 & ns & $100-200$ & 0 & 0 & ns & $€ / \mathrm{m}$ & 2012 & [108] \\
\hline 132 & ns & $200-600$ & 0 & 0 & ns & $€ / \mathrm{m}$ & 2012 & [108] \\
\hline
\end{tabular}

* Range calculated from given conductor CSA in [93] and current ratings in [109].

Table A2. Dynamic cable cost coefficients.

\begin{tabular}{|c|c|c|c|c|c|c|c|c|}
\hline \multicolumn{2}{|c|}{ Voltage (kV) } & \multicolumn{3}{|c|}{ Cost Coefficient } & \multirow{2}{*}{$\begin{array}{l}\text { Range } \\
\text { (MVA) }\end{array}$} & \multirow{2}{*}{ Units } & \multirow{2}{*}{ Year } & \multirow{2}{*}{ Ref. } \\
\hline Rated & $\operatorname{Max}$ & c1 & c2 & c3 & & & & \\
\hline 6.6 & 7.2 & 94.69 & 11.54 & 0.44 & {$[2.9,7.5]$} & $\mathrm{k} € / \mathrm{km}$ & - & - \\
\hline 11 & 12 & 69.12 & 22.85 & 0.22 & {$[4.8,12.5]$} & $\mathrm{k} € / \mathrm{km}$ & - & - \\
\hline 22 & 24 & -1.78 & 70.92 & 0.07 & {$[9.5,27.2]$} & $\mathrm{k} € / \mathrm{km}$ & - & - \\
\hline 33 & 36 & -49.42 & 112.20 & 0.041 & {$[17.0,44.0]$} & $\mathrm{k} € / \mathrm{km}$ & - & - \\
\hline MV & ns & $300-800$ & 0 & 0 & ns & $€ / \mathrm{m}$ & 2013 & [47] \\
\hline
\end{tabular}


Table A3. Transformer cost coefficients.

\begin{tabular}{|c|c|c|c|c|c|c|c|c|}
\hline \multirow{2}{*}{ Voltage } & \multirow{2}{*}{ Type } & \multicolumn{3}{|c|}{ Cost Coefficient } & \multirow{2}{*}{$\begin{array}{l}\text { Range } \\
\text { (MVA) }\end{array}$} & \multirow{2}{*}{ Units } & \multirow{2}{*}{ Year } & \multirow{2}{*}{ Ref. } \\
\hline & & c1 & c2 & c3 & & & & \\
\hline \multirow{2}{*}{ LV:MV } & Dry & $6.496 \times 10^{4}$ & 0.6329 & $7.307 \times 10^{3}$ & {$[0.1125,3]$} & U.S. \$ & - & - \\
\hline & Wet & $45.48 \times 10^{4}$ & 0.6329 & $51.115 \times 10^{3}$ & {$[0.1125,3]$} & U.S. \$ & - & - \\
\hline \multirow{2}{*}{ MV:MV } & Dry & $2.629 \times 10^{4}$ & 1 & 0 & {$[5.0,100]$} & U.S. \$ & - & - \\
\hline & Wet & $18.4 \times 10^{4}$ & 1 & 0 & {$[5.0,100]$} & U.S. \$ & - & - \\
\hline \multirow{2}{*}{ MV:HV } & Dry & $2.156 \times 10^{4}$ & 1 & 0 & {$[5,100]$} & U.S. \$ & - & - \\
\hline & Wet & $15.09 \times 10^{4}$ & 1 & 0 & {$[5,100.0]$} & U.S. \$ & - & - \\
\hline \multirow{2}{*}{$\begin{array}{c}\text { MV:HV } \\
\text { ns }\end{array}$} & Dry & 1.034 & 0.448 & -1.206 & {$[6.3,150]$} & MSEK & 2003 & [32] \\
\hline & ns & $4-6 \times 10^{4}$ & 1 & 0 & ns & $€$ & 2013 & [47] \\
\hline MV:HV & Dry & 0.004761 & 1.074 & 0.3426 & {$[30,120]$} & $\mathrm{M} £$ & 2008 & [93] \\
\hline \multirow{2}{*}{$\begin{array}{c}\text { MV:HV } \\
\text { ns }\end{array}$} & ns & $8.5 \times 10^{3}$ & 1 & 0 & ns & $€$ & 2005 & [110] \\
\hline & ns & 0.03422 & 0.7472 & $-0.008 .57 \times 10^{-3}$ & {$[40,800]$} & $\mathrm{M} €$ & 2005 & [111] \\
\hline
\end{tabular}

Table A4. Switchgear cost coefficients.

\begin{tabular}{ccccccc}
\hline \multirow{2}{*}{ Type } & \multicolumn{2}{c}{ Cost Coefficient } & Range & Units & Year & Ref. \\
\cline { 2 - 4 } & $\mathbf{c 1}$ & $\mathbf{c 2}$ & $\mathbf{( k V )}$ & & & \\
\hline Breaker & 2.975 & $80 \times 10^{3}$ & {$[0,400]$} & SEK & 2003 & {$[32]^{*}$} \\
Disconnector & 0.6 & $2 \times 10^{3}$ & {$[0,400]$} & SEK & 2003 & {$[32]^{*}$} \\
Sensor & 0.325 & $2 \times 10^{3}$ & {$[0,400]$} & SEK & 2003 & {$[32]^{*}$} \\
Cubicle & 6 & $320 \times 10^{3}$ & {$[0,400]$} & SEK & 2003 & {$[32]$} \\
Device & 2.8726 & $100.33 \times 10^{3}$ & {$[0,66]$} & SEK & 2003 & {$[32]$} \\
Device & 0 & $60-100$ & ns & $€ / k W$ & 2013 & {$[47]$} \\
\hline
\end{tabular}

* Cost coefficients are not directly supplied, but have been obtained from original data presented in the reference; ns = not stated

Table A5. FACTS cost coefficients.

\begin{tabular}{|c|c|c|c|c|c|c|c|}
\hline \multirow{2}{*}{ Type } & \multicolumn{3}{|c|}{ Cost Coefficient } & \multirow{2}{*}{$\begin{array}{c}\text { Range } \\
\text { (MVAr) }\end{array}$} & \multirow{2}{*}{ Year } & \multirow{2}{*}{ Units } & \multirow{2}{*}{ Ref. } \\
\hline & c1 & c2 & c3 & & & & \\
\hline Shunt capacitor & 0 & 0 & 8 & ns & 1995 & U.S. \$/kVAr & [90] \\
\hline Series capacitor & 0 & 0 & 20 & ns & 1995 & U.S. \$/kVAr & [90] \\
\hline SVC & 0 & 0 & 40 & ns & 1995 & U.S. \$/kVAr & [90] \\
\hline STATCOM & 0 & 0 & 50 & ns & 1995 & U.S. \$/kVAr & [90] \\
\hline TCSC & 0 & 0 & 40 & ns & 1995 & U.S. \$/kVAr & [90] \\
\hline SVC & 0.0002 & -0.1736 & 74.5 & {$[100,400]$} & 2008 & U.S. \$/kVAr & [91] \\
\hline STATCOM & 0.0002 & -0.1958 & 106.4 & {$[100,400]$} & 2008 & U.S. \$/kVAr & [91] \\
\hline TCSC & 0.00151 & -0.6451 & 119.2 & {$[25,200]$} & 2008 & U.S. \$/kVAr & [91] \\
\hline
\end{tabular}

Table A6. Component manufacturing lead times.

\begin{tabular}{ccc}
\hline Component & Lead Time (Month) & Ref. \\
\hline Cable & $24-36$ & {$[108]$} \\
Connector & $3-8$ & {$[43]$} \\
Transformer & $12-36 *$ & {$[108,112]$} \\
Switchgear & 6 & {$[112]$} \\
Capacitor bank & 5 & {$[108]$} \\
MV Harmonic filter & 5 & {$[108]$} \\
HV Harmonic filter & $9-12$ & {$[108]$} \\
Reactor & $12-24$ & {$[108]$} \\
FACTS device & $12-24$ & {$[108]$} \\
Turnkey substation & 24 & {$[108]$} \\
\hline
\end{tabular}

* Without significant market demand, this can be as low as nine months [112]. 


\section{References}

1. Huckerby, J.; Jeffrey, H.; de Andres, A.; Finlay, L. An International Vision for Ocean Energy; Technical Report for Ocean Energy Systems; Ocean Energy Systems: Lisbon, Portugal, 2017.

2. European Ocean Energy Association. European Ocean Energy: Industry Vision Paper 2013; European Ocean Energy Association: Brussel, Belgium, 2013.

3. Magagna, D.; Monfardini, R.; Uihlein, A. JRC Ocean Energy Status Report: Technology, Market and Economic Aspects of Ocean Energy in Europe; Technical Report JRC104799; Publications Office of the European Union: Luxembourg City, Luxembourg, 2016.

4. Wind Europe. Wind in Power: 2016 European Statistics; Wind Europe: Brussels, Belgium, 2016.

5. JRC Ocean. DTOCEAN Suite (Version 1). Windows. 2016. Available online: https://setis.ec.europa.eu/dtocean/ (accessed on 30 October 2017).

6. De, O.; Falcao, A.F. Wave energy utilization: A review of the technologies. Renew. Sustain. Energy Rev. 2010, 14, 899-918.

7. Santos, M.; Salcedo, F.; Ben Haim, D.; Mendia, J.L.; Ricci, P.; Villate, J.L.; Khan, J.; Leon, D.; Arabi, S.; Moshref, A.; et al. Integrating Wave and Tidal Current Power: Case Studies through Modelling and Simulation; Technical Report T0331; International Energy Agency: Paris, France; Ocean Energy Systems: Lisbon, Portugal, March 2011.

8. Mason, A. Marine Energy Electrical Architecture, Report 1: Landscape Map and Literature Review; TNEI Technical Report PN000083-LRT-006; ORE Catapult: Glasgow, UK; Carbon Trust: London, UK, September 2015.

9. Mason, A.; Driver, R. Marine Energy Electrical Architecture, Report 3: Optimum Electrical Array Architectures; TNEI Technical Report PN000083-LRT-008; ORE Catapult: Glasgow, UK; Carbon Trust: London, UK, September 2015.

10. ITP Energised. PTEC Developer Consultation Report; Technical Report UKP1191; ITP Energised: Bristol, UK, October 2013.

11. Petie, M.; Platt, N.; Crimin, S. Final Report for Phase 2 for Electrical Infrastructure of Commercial Scale Tidal Power Array. Available online: https://www.scottish-enterprise.com/ /media/se/resources/documents/ stuv/Tidal-Electrical-Architecture-Report-Siemens (accessed on 30 October 2017).

12. Brown, G.V. Proposal for a Commercial Scale Tidal Array Concept Study. Available online: https://www.scottish-enterprise.com/ /media/se/resources/documents/stuv/Tidal-ElectricalArchitecture-Report-ABB (accessed on 30 October 2017).

13. Mumtaz, D. Electrical Infrastructure Required for Commercial Scale Tidal Power Arrays: Selection of Turbine Collection Topology. Technical Report Rev 4, GE. 2013. Available online: https:/ / www.scottish-enterprise. $\mathrm{com} / \sim /$ media/se/resources/documents/stuv/Tidal-Electrical-Architecture-Report-GE (accessed on 30 October 2017).

14. MeyGen Limited. MeyGen Phase 1a Project Description. Available online: http://www.meygen.com/aboutphase-1a/ (accessed on 30 October 2017).

15. McPherson, G. Construction Method Statement: Shetland Tidal Array, Bluemull Sound. Available online: http:/ / www.gov.scot/Topics/marine/Licensing/marine/scoping/nova/CMS-20160516 (accessed on 30 October 2017).

16. McPherson, G. Bluemull Sound Tidal Array Cable Plan; Technical Report; Nova Innovation Ltd.: Edinburgh, UK, 2015. Available online: http:/ / www.gov.scot/Resource/0050/00501686.pdf (accessed on 30 October 2017).

17. Lewis, M.; Neill, S.P.; Robins, P.E.; Hashemi, M.R. Resource Assessment for Future Generations of Tidal-Stream Energy Arrays. Energy 2015, 83, 403-415.

18. Lewis, M.J.; Angeloudis, A.; Robins, P.E.; Evans, P.S.; Neill, S.P. Influence of Storm Surge on Tidal Range Energy. Energy 2017, 122, 25-36.

19. Bala, S.; Pan, J.; Barlow, G.; Brown, G.; Ebner, S. Power Conversion Systems for Tidal Power Arrays. In Proceedings of the IEEE 5th International Symposium on Power Electronics for Distributed Generation Systems (PEDG), Galway, Ireland, 24-27 June 2014; pp. 1-7.

20. The Crown Estate. U.K. Wave and Tidal Key Resource Areas Project; The Crown Estate: London, UK, 2013.

21. Worzyk, T. Submarine Power Cables: Design, Installation, Repair, Environmental Aspects; Springer: Berlin, Germany, 2009; ISBN 978-3-642-01269-3. 
22. 4C Offshore Transmission Systems. Available online: http://www.4coffshore.com/windfarms/ts.aspx (accessed on 30 October 2017).

23. 4Coffshore. Offshore Wind Farms. Available online: http://www.4coffshore.com/windfarms/ (accessed on 30 October 2017).

24. TenneT. 66 kV Systems for Offshore Wind Farms; Technical Report 113799-UKBR-R02, Rev. 2; DNV GL Energy: Arnhem, The Netherlands, March 2015.

25. MacLeod, N.; Callavik, M.; Boden, M.; Dhesi, M.; Huuva, R.; Kuljaca, N.; Schettler, F. A Technological Roadmap for the Development of the European Supergrid. In Proceedings of the Cigre International Symposium-HVDC Systems and Markets Integration, Lund, Sweden, 27-28 May 2015.

26. Sharples, M. Offshore Electrical Cable Burial for Wind Farms: State of the Art, Standards and Guidance and Acceptable Burial Depths, Separation Distances and Sand Wave Effect; Technical Report; U.S. Bureau of Ocean Energy Management, Regulation and Enforcement: Washington, DC, USA, November 2011.

27. Det Norske Veritas. Subsea Power Cables in Shallow Water Renewable Energy Applications; Det Norske Veritas: Høvik, Norway, 2014.

28. Carbon Trust. Cable Burial Risk Assessment Methodology; Technical Report CTC835; Carbon Trust: London, UK, February 2015.

29. Det Norske Veritas. On-Bottom Stability Design of Submarine Pipelines; DNV-RP-F109; Det Norske Veritas: Høvik, Norway, 2010.

30. Scottish Power Renewables. Sound of Islay Demonstration Tidal Array: Cable Route Environmental Information; Technical Report; Scottish Power Renewables: Belfast, UK, May 2013.

31. Wave Hub Limited. Wave Hub: Advancing Offshore Renewable Energy. Available online: https://www. wavehub.co.uk/ (accessed on 30 October 2017).

32. Lundberg, S. Performance Comparison of Wind Park Configuration; Technical Report 30R; Chalmers University of Technology: Goteborg, Sweden, 2003.

33. Technip. Umbilical Systems: Customised Umbilical Systems for the Global Offshore Oil and Gas Market. 2011. Available online: http:/ / www.technip.com/sites/default/files/technip/fields/fr_umbilical_systems. pdf (accessed on 30 October 2017).

34. Infield Systems. Deep \& Ultra-deepwater Technology \& Projects Report 2008-12; Infield Systems: London, UK, 2012.

35. European Wind Energy Association. Deep Water; Technical Report 978-2-930670-04-1; European Wind Energy Association: Brussels, Belgium, July 2013; ISBN 978-2-930670-04-1.

36. James, R.; Ros, M.C. Floating OffshoreWind: Market and Technology Review; Technical Report CTC840v2; Carbon Trust: London, UK, June 2015.

37. Govindji, A.-K.; James, R.; Carvallo, A. Appraisal of the Offshore Wind Industry in Japan; Technical Report CTC834; Carbon Trust: London, UK, 2014. Available online: https://www.carbontrust.com/media/566323/ ctc834-detailed-appraisal-of-the-offshore-wind-industry-in-japan.pdf ( accessed on 30 October 2017).

38. International Umbilical Manufacturers' Federation. Experience Report: Control Umbilicals Delivered by UMF Members in the Period 1995-2000; International Umbilical Manufacturers' Federation: Oslo, Norway, 2004.

39. Teledyne. 107 Series Connectors. Available online: http:/ / www.teledynemarine.com/Lists/Downloads / DGO_107\%20Series\%20Technical\%20Data.pdf (accessed on 30 October 2017).

40. Teledyne. 100 Series Connector. Available online: http://www.teledynemarine.com/Lists/Downloads/ DGO-100_Series_Connectors-549307.pdf (accessed on 30 October 2017).

41. SEACON. SEACON 55 \& 66 Series: Underwater Dry-mate Electrical Connectors; Technical Report Rev VII; SEACON: El Cajon, CA, USA, 2015.

42. Cooper Interconnectors. Subsea Connectors. 2012. Available online: http://subsea-supplies.co.uk/ fileuploader /download/download/?d=1\&file=custom\%2Fupload\%2FFile-1430922181.pdf (accessed on 30 October 2017).

43. Wood Group Kenny. Wet Mate Connector Market Study; Technical Report 2500014-01-D-3-001; ORE Catapult: Glasgow, UK, 2014. Available online: https:/ / ore.catapult.org.uk/wp-content/uploads/2016/05/Wet-mateconnector-study.pdf (accessed on 30 October 2017).

44. Chen, Q. Subsea High Voltage Direct Current Connectors for Environmentally Safe and Reliable Oowering of UDW Subsea Processing. In Proceedings of the PSEA/SPE-GCS Ultra-Deepwater Technology Conference, Houston, TX, USA, 3-4 September 2015. 
45. Mulcahy, M. 46 Years of Subsea Connector Excellence; Ocean News and Technology: Stuart, FL, USA, 2014. Available online: http:/ / seaconworldwide.com/wp-content/uploads/Ocean-News-Technology-September-2014.pdf (accessed on 30 October 2017).

46. Pye, D. Subsea Connectors for Marine Renewable Energy Applications. In Proceedings of the 5th International Conference on Ocean Energy, Halifax, NS, Canada, 4-6 November 2014.

47. Alcorn, R.; O'Sullivan, D. Electrical Design for Ocean Wave and Tidal Energy Systems; IET Renewable Energy Series; Institution of Engineering and Technology: London, UK, 2013; ISBN 978-1-84919-561-4.

48. Pye, D.; Mulcahy, M. Connections for the Marine Renewables Industry; International Ocean Systems: London, UK, 2014. Available online: http://www.intoceansys.co.uk/articles-detail.php?iss=0000000042\&acl= 0000000360 (accessed on 30 October 2017).

49. Burrows, A. Lowering the Cost of Marine Energy with Affordable Subsea Connection Solutions. In Proceedings of the 5th International Conference on Ocean Energy, Halifax, NS, Canada, 4-6 November 2014.

50. Wyatt, R. Lowering the Cost of Marine Energy: Affordable Connection Solutions. In Proceedings of the All Energy 2013 Exhibition \& Conference, Aberdeen, UK, 22-23 May 2013.

51. Carbon Trust. Accelerating Marine Energy; Technical Report CTC797; Carbon Trust: London, UK, July 2011.

52. Pye, D. Subsea Connectors in the Marine Renewable Energy Sector. 2014. Available online: http://seaconworldwide.com/wp-content/uploads/SEA-CON-Article_ECO_FINAL.pdf (accessed on 30 October 2017).

53. International Electrotechnical Commission. Mobile and Fixed Offshore Units: Electrical Installations; IEC 61892-1; International Electrotechnical Commission: Geneva, Switzerland, 2015.

54. Det Norske Veritas. Electrical Installations; DNVGL-OS-D201; Det Norske Veritas: Høvik, Norway, 2015.

55. Institution of Electrical Engineers. Recommendations for the Electrical and Electronic Equipment of Mobile and Fixed Offshore Installations; IEE PWR04010; Institution of Electrical Engineers: Stevenage, UK, 1992.

56. Gardner, P.; Craig, L.M.; Smith, G.J. Electrical Systems for Offshore Wind Farms. In Proceedings of the 20th British Wind Energy Association Conference, Cardiff, UK, 2-4 September 1998; pp. 309-317.

57. Declercq, J.; Schevensteen, R.V. Challenges for Reliable Offshore Transformers: Maximising the Value of Wind Energy; Windtech International: Groningen, The Netherlands, 2008. Available online: http:/ / static.mimaterials.com/midel/documents/sales/Challenges\%20For\%20Reliable\%20Offshore\% 20Transformers.pdf (accessed on 30 October 2017).

58. Al-Amin, H.; O’Brien, J.; Lashbrook, M. Synthetic Ester Transformer Fluid: A Total Solution to Windpark Transformer Technology. Renew. Energy 2013, 49, 33-38.

59. Siemens. New AC Grid Access: Offshore Transformer Module. 2015. Available online: http://www.ptd. siemens.de/AC_Flyer_GA.pdf (accessed on 30 October 2017).

60. ABB. ABB to Supply Special Transformers for the World's Most Powerful Wind Turbines. Available online: http://www.abb.com/cawp/seitp202/5c965542b4aebe0cc1257fa7002d1d49.aspx (accessed on 30 October 2017).

61. Siemens. 66 Kilovolt Transformer and Switchgear Option for Siemens Offshore Wind Turbines Available. 2016. Available online: https://www.siemens.com/press/en/pressrelease/?press=/en/pressrelease/2016/ windpower-renewables/pr2016090420wpen.htm (accessed on 30 October 2017).

62. Gordian, RSMeans. Available online: https://www.rsmeansonline.com/ (accessed on 30 October 2017).

63. Harder, S. Business Development Specialist, Transformers, Siemens, Munich, Germany. Personal communication, January 2015.

64. Brath, B.E. OTC 2010 X-pert Center: Subsea Power Grid; Siemens: Munich, Germany, 2010. Available online: https:/ / www.energy.siemens.com/us/pool/hq/energy-topics/tradeshows/2010otc/downloads/ Subsea\%20Power\%20Grid_b.pdf (accessed on 30 October 2017).

65. Virtanen, E.; Akdag, A. Power below the Waves; Technical Report; ABB Group: Zürich, Switzerland, May 2013.

66. GE Oil \& Gas. Subsea Power \& Processing: Increasing Recovery and Optimizing Performance; Technical Report GE_SS_Power_Processing-031016; GE Oil \& Gas: London, UK, March 2016.

67. Bergeli, E. Sales Manager Subsea Electrification. ABB Group, Zürich, Switzerland. Personal communication, December 2014. 
68. Siemens. Subsea Transformer. Available online: https://w3.siemens.com/markets/global/en/oil-gas/ PublishingImages/applications/subsea/products/subsea-power-grid/subsea-transformer-siemens.pdf (accessed on 30 October 2017).

69. Energinet. Offshore Transformer Platform; Energinet 44854-09-rev1; Energinet: Erritsø, Denmark, 2009.

70. Institute of Electrical and Electronics Engineers (IEEE). IEEE Standard for General Requirements for Liquid-Immersed Distribution, Power, and Regulating Transformers; IEEE Std C57.12.00-2015; IEEE: Piscataway, NJ, USA, 2016.

71. International Electrotechnical Commission. Environmental Testing_Part 1: General and Guidance; IEC 60068-1 2013; International Electrotechnical Commission: Geneva, Switzerland, 2013.

72. ABB. Super-Slim Wind Switchgear SafeWind. Available online: http://new.abb.com/medium-voltage/ switchgear/safewind (accessed on 30 October 2017).

73. Ormazabal Velatia. Medium Voltage Switchgear for Distribution Network Solutions. Available online: https: / / www.ormazabal.com/sites/default/ files/descargas/ca-112-en-1611.pdf (accessed on 30 October 2017).

74. Siemens. Gas Insulated Switchgear. Available online: https://www.energy.siemens.com/us/en/powertransmission/high-voltage-products/gas-insulated-switchgear/ (accessed on 30 October 2017).

75. Siemens. Connecting Wind Power to the Grid-Gas-Insulated Medium-Voltage Switchgear for Wind Farms. Available online: https://w3.siemens.com/powerdistribution/global/SiteCollectionDocuments/en/mv / switchgear/gas-insulated/nxplus-c-wind/brochure-connecting-wind-power-to-the-grid_en.pdf (accessed on 30 October 2017).

76. 4C Offshore. Buitengaats (Substation). Available online: http://www.4coffshore.com/windfarms/ substation-buitengaats-sid136.html (accessed on 30 October 2017).

77. Siemens. Gas-Insulated Switchgear up to 245 kV, 50 kA, 4000 A Type 8DN9. Available online: http:/ / www. siemens.co.in/pool/about_us/our_business_segments/gis_245kv_2.pdf (accessed on 30 October 2017).

78. Schaffer, J.S.; Hazel, T. Ensuring Switchgear Integrity in High-Power Installations. IEEE Trans. Ind. Appl. 2015, 51, 2641-2650.

79. Hazel, T.; Baerd, H.; Bremnes, J.J.; Legeay, J. Subsea high-voltage power distribution. In Proceedings of the 58th Annual IEEE Petroleum and Chemical Industry Conference (PCIC), Toronto, ON, Canada, 19-21 September 2011; pp. 1-9.

80. Hazel, T. Impact of Subsea Processing Power Distribution: Subsea Switchgear Module a Key Enabling Component in Subsea Installations; Technical Report 998-4670 GMA; Schneider Electric: Rueil-Malmaison, France, July 2011.

81. S \& C Electric Company. 60-MVAR Reactive Compensation System Helps Connect One of the UK's Largest Wind Farms. 2015. Available online: http://www.all-energy.co.uk/_novadocuments/253685?v= 636051478306930000 (accessed on 30 October 2017).

82. Siemens. SVC PLUS (VSC Technology). Available online: http://www.energy.siemens.com/mx/en/ power-transmission/facts/static-var-compensator-plus/converter.htm\#content=References (accessed on 30 October 2017).

83. Siemens. Improvement in Voltage Quality for Power Systems-With SVC PLUS. Available online: http: //www.ptd.siemens.de/ETG1009_SVCPLUS.pdf (accessed on 30 October 2017).

84. 4C Offshore. Greater Gabbard-Galloper Array Substation. Available online: http://www.4coffshore. com/windfarms/substation-greater-gabbard---galloper-array-substation-sid34.html (accessed on 30 October 2017).

85. ABB. ABB PCS 6000 STATCOM Enables Further Growth of Europe's Largest Wind Farm. 2012. Available online: http:/ /www.abb.com/cawp/seitp202/d9b74eb2491d55d9c1257ac2004801f7.aspx (accessed on 30 October 2017).

86. Yang, Z.; Shen, C.; Zhang, L.; Crow, M.L.; Atcitty, S. Integration of a StatCom and battery energy storage. IEEE Trans. Power Syst. 2001, 16, 254-260.

87. Mahmud, M.; Hossain, M.; Pota, H. Analysis of Voltage Rise Effect on Distribution Network with Distributed Generation. In Proceedings of the 18th World Congress of the International Federation of Automatic Control, Milan, Italy, 29 August-2 September 2011; pp. 14796-14801.

88. Santos, M.; Blavette, A.; Tedeschi, E.; O'Sullivan, D.; Salced, F. Case Study on the Benefits of Energy Storage for Power Quality Enhancement: Point Absorber Arrays. In Proceedings of the International Conference on Ocean Energy, Dublin, Ireland, 17-19 October 2012. 
89. Blavette, A.; O'Sullivan, D.L.; Lewis, T.W.; Egan, M.G. Dimensioning the Equipment of a Wave Farm: Energy Storage and Cables. IEEE Trans. Ind. Appl. 2015, 51, 2470-2478.

90. IEEE Power Engineering Society; International Council on Large Electric Systems (CIGRE). FACTS Overview; Technical Report 95TP108; IEEE Power Engineering Society: Piscataway, NJ, USA, 1995.

91. Habur, K.; O'Leary, D. FACTS_Flexible Alternating Current Transmission Systems for Cost Effective and Reliable Transmission of Electrical Energy. 2008. Available online: http:/ / sites.google.com/site/lawking/facts_siemens. pdf (accessed on 30 October 2017)

92. De Sandt, R.V.; Lowen, J.; Paetzold, J.; Erlic, I. Neutral Earthing in Off-Shore Wind Farm Grids. In Proceedings of the IEEE PES PowerTech, Bucharest, Romania, 28 June-2 July 2009; pp. 1-8.

93. Djapic, P.; Strbac, G. Cost Benefit Methodology for Optimal Design of Offshore Transmission Systems; Technical Report RN 08/1144; Centre for Sustainable Electricity and Distributed Generation, Department for Business Enterprise and Regulatory Reform: London, UK, July 2008.

94. Valov, B. Transformers for Offshore Wind Platforms: Expected Problems and Possible Approaches. In Proceedings of the 8th International Workshop on Large-Scale Integration of Wind Power into Power Systems as well as on Transmission Networks for Offshore Wind Farms, Bremen, Germany, 14-15 October 2009.

95. National Grid. National Electricity Transmission System: Security and Quality of Supply Standard; National Grid: London, UK, 2012.

96. Fukushima Offshore Wind Consortium. Fukushima Floating Offshore Wind Farm Demonstration Project. Available online: http:/ / www.fukushima-forward.jp/pdf/pamphlet3.pdf (accessed on 30 October 2017).

97. Siemens Energy. Subsea Solutions: Enabling Subsea Processing by Connecting Innovation with Experience; Technical Report E50001-G440-A148-V2-4A00; Siemens Energy: Erlangen, Germany, 2014.

98. MARINA Project. Efficient Solutions for Energy Pickup and Transport to Grid Connection Point On-Shore. Available online: http:/ / cordis.europa.eu/project/rcn/93425_en.html (accessed on 30 October 2017).

99. Ocean Power Technologies. Underwater Substation Pod. 2008. Available online: https:/ /www.macartney. com/media/3434/usp-brochure_may-2008.pdf (accessed on 30 October 2017).

100. Rahm, R.; Bostrom, C.; Svensson, O.; Grabbe, M.; Bulow, F.; Leijon, M. Offshore Underwater Substation for Wave Energy Converter Arrays. IET Renew. Power Gener. 2010, 4, 602-612, doi:10.1049/iet-rpg.2009.0180.

101. Hydro Group. Power Take Offs. PDH: Power Distribution Hub. Available online: http:/ / www.hydrogroupplc. com/datasheets/PDH_Power_Distribution_Hub_Hydro_Group_plc.pdf (accessed on 30 October 2017).

102. MacArtney Underwater Technology. GreenLink Hub Modular: Underwater Termination Units. Available online: https: / www.macartney.com/media/5263/greenlink-hub.pdf (accessed on 30 October 2017).

103. GE Renewable Energy. GE's Tidal Stream Solutions; Technical Report GEA32275; GE Renewable Energy: Fairfield, CT, USA, 2015.

104. Seabased. Seabased and Wave Power. 2016. Available online: https://www.energimyndigheten. se/globalassets/forskning--innovation/konferenser/havsenergiforum2016/seabased.pdf (accessed on 30 October 2017).

105. 4C Offshore. Offshore Substations Database. Available online: http://www.4coffshore.com/windfarms / substations.aspx (accessed on 30 October 2017).

106. DTOCEAN: Design and Optimisation Tools for Ocean Energy Arrays. Available online: http://www. dtocean.eu/ (accessed on 30 October 2017).

107. Green, R.; Vasilakos, N. The Economics of Offshore Wind. Energy Policy 2011, 39, 496-502.

108. RPS; TNEI; PPA Energy; Royal IHC; Scottish Government; Irish Government; Northern Irish Executive. Irish-Scottish Links on Energy Study (ISLES): Technology Roadmap Report; Technical Report; Irish Department of Communications, Climate Action and Environment: Dublin, Ireland, April 2012.

109. ABB. XLPE Submarine Cable Systems. Available online: http:/ /www04.abb.com/global/seitp/seitp202. nsf/0/badf833d6cb8d46DC1257c0b002b3702/ /protect \T1 \textdollarfile/XLPE+Submarine+Cable+ Systems+2GM5007+.pdf (accessed on 30 October 2017).

110. Pantaleo, A.; Pellerano, A.; Ruggiero, F.; Trovato, M. Feasibility Study of off-shore Wind Farms: An Application to Puglia region. Sol. Energy 2005, 79, 321-331. 
111. Lazaridis, L.P. Economic Comparison of HVAC and HVDC Solutions for Large Offshore Wind Farms under Special Consideration of Reliability. Master's Thesis, Royal Institute of Technology, Stockholm, Sweden, 2005.

112. Power Technology. Transformers and Switchgear: Where Is It All Going? 2008. Available online: http: / / www.power-technology.com/features/feature40480/ (accessed on 30 October 2017).

(C) 2017 by the authors. Licensee MDPI, Basel, Switzerland. This article is an open access article distributed under the terms and conditions of the Creative Commons Attribution (CC BY) license (http:// creativecommons.org/licenses/by/4.0/). 